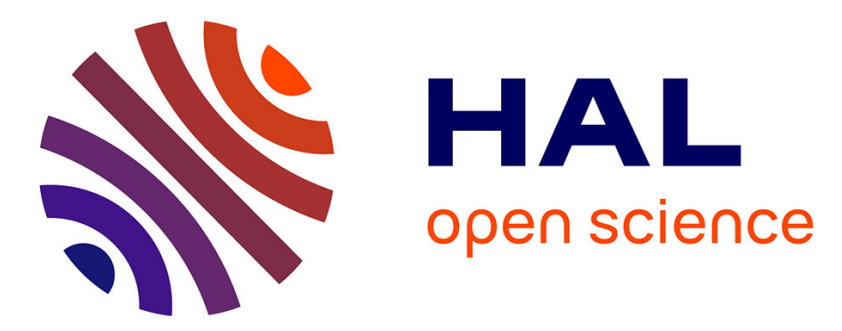

\title{
Formation of slip bands and microstructure evolution of Ti-5Al-5Mo-5V-3Cr-0.5Fe alloy during warm deformation process
}

\author{
Jiangkun Fan, Hongchao Kou, Yudong Zhang, Lionel Germain, Ke Hua, \\ Luyao Tang, Claude Esling, Jinshan Li
}

\section{To cite this version:}

Jiangkun Fan, Hongchao Kou, Yudong Zhang, Lionel Germain, Ke Hua, et al.. Formation of slip bands and microstructure evolution of Ti-5Al-5Mo-5V-3Cr-0.5Fe alloy during warm deformation process. Journal of Alloys and Compounds, 2018, 770 (10), pp.183-193. 10.1016/j.jallcom.2018.08.097 . hal02483380

\author{
HAL Id: hal-02483380 \\ https://hal.science/hal-02483380
}

Submitted on 18 Feb 2020

HAL is a multi-disciplinary open access archive for the deposit and dissemination of scientific research documents, whether they are published or not. The documents may come from teaching and research institutions in France or abroad, or from public or private research centers.
L'archive ouverte pluridisciplinaire $\mathbf{H A L}$, est destinée au dépôt et à la diffusion de documents scientifiques de niveau recherche, publiés ou non, émanant des établissements d'enseignement et de recherche français ou étrangers, des laboratoires publics ou privés. 


\section{Accepted Manuscript}

Formation of slip bands and microstructure evolution of Ti-5Al-5Mo-5V-3Cr- $0.5 \mathrm{Fe}$ alloy during warm deformation process

Jiangkun Fan, Hongchao Kou, Yudong Zhang, Lionel Germain, Ke Hua, Luyao Tang, Claude Esling, Jinshan Li

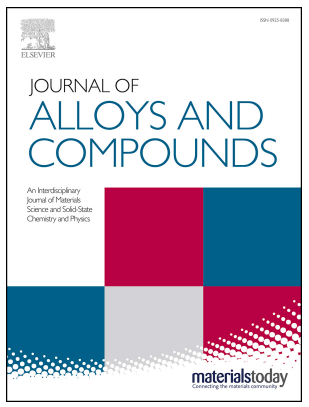

PII: S0925-8388(18)32970-0

DOI: 10.1016/j.jallcom.2018.08.097

Reference: JALCOM 47185

To appear in: Journal of Alloys and Compounds

Received Date: 29 December 2017

Revised Date: 9 August 2018

Accepted Date: 11 August 2018

Please cite this article as: J. Fan, H. Kou, Y. Zhang, L. Germain, K. Hua, L. Tang, C. Esling, J. Li, Formation of slip bands and microstructure evolution of Ti-5Al-5Mo-5V-3Cr-0.5Fe alloy during warm deformation process, Journal of Alloys and Compounds (2018), doi: 10.1016/j.jallcom.2018.08.097.

This is a PDF file of an unedited manuscript that has been accepted for publication. As a service to our customers we are providing this early version of the manuscript. The manuscript will undergo copyediting, typesetting, and review of the resulting proof before it is published in its final form. Please note that during the production process errors may be discovered which could affect the content, and all legal disclaimers that apply to the journal pertain. 


\section{Graphical Abstract}
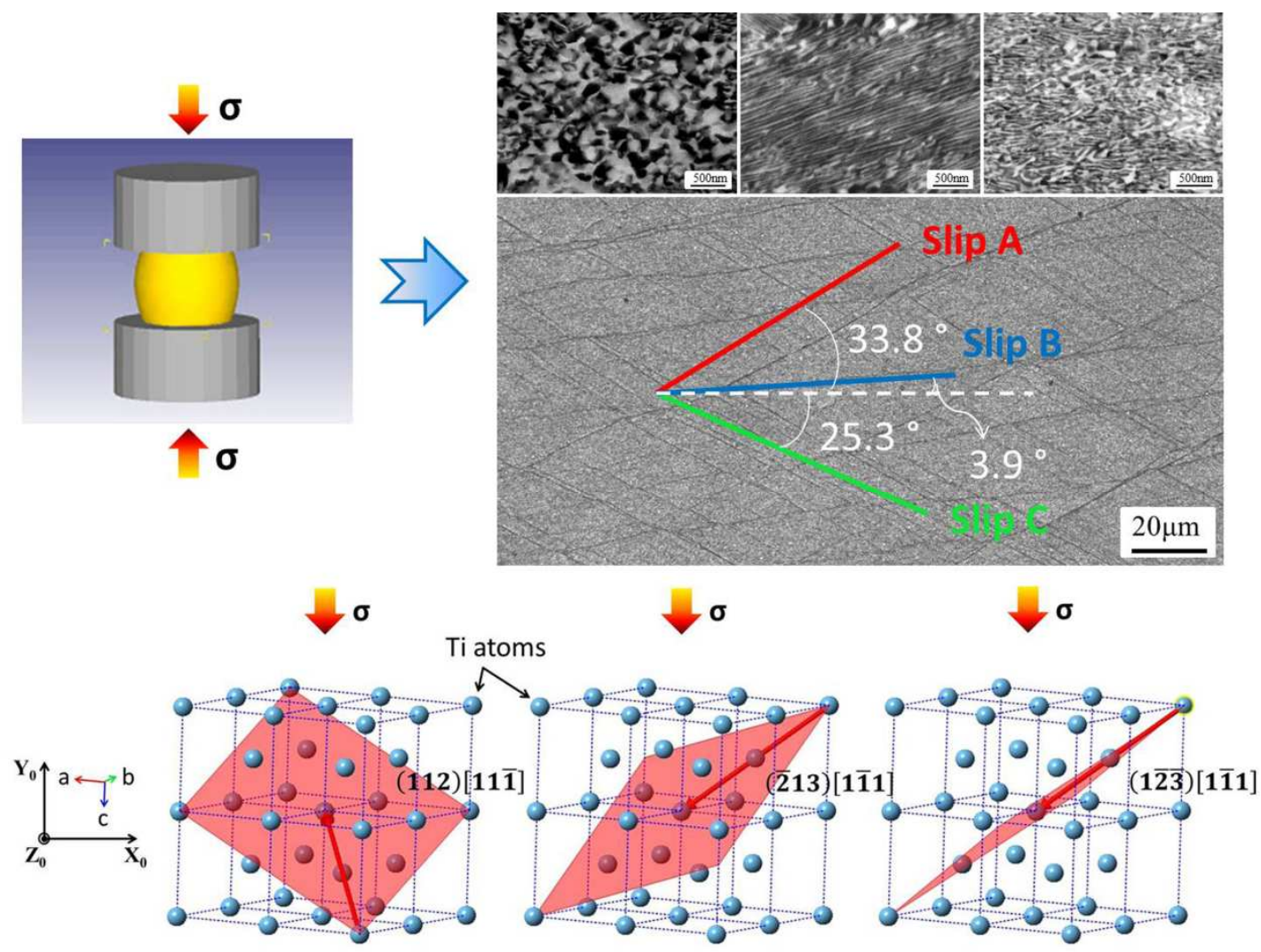


\title{
Formation of slip bands and microstructure evolution of
}

\section{Ti-5Al-5Mo-5V-3Cr-0.5Fe alloy during warm deformation process}

\author{
Jiangkun Fan ${ }^{\text {a,b * }}$, Hongchao Kou ${ }^{\text {a,b }}$, Yudong Zhang ${ }^{\text {c,d }}$, Lionel Germain ${ }^{\text {c,d }}$, Ke Hua ${ }^{\text {a,c }}$, \\ Luyao Tang ${ }^{\text {a }}$, Claude Esling ${ }^{\text {c,d }}$, Jinshan $\mathrm{Li}^{\text {a,b }}$
}

${ }^{a}$ State Key Laboratory of Solidification Processing, Northwestern Polytechnical University, Xi'an 710072, P.R. China

${ }^{\mathrm{b}}$ National \& Local Joint Engineering Research Center for Precision Thermoforming Technology of Advanced Metal Materials, Xi'an, Shaanxi 710072, P.R. China

${ }^{c}$ Laboratoire d'Étude des Microstructures et de Mécanique des Matériaux (LEM3), CNRS 7239, Université de Lorraine, 57045 Metz, France

${ }^{\mathrm{d}}$ Laboratory of Excellence on Design of Alloy Metals for low-mAss Structures (DAMAS), Université de Lorraine, 57045 Metz, France

\begin{abstract}
The characteristics of slip band and its interplay with dynamic precipitation of $\alpha$ phase during the thermo-mechanical coupling process in titanium alloy is really interesting but is not sufficiently ascertain. In the present work, the formation of slip bands, dynamic microstructure evolution and crystallographic orientation relationship during warm deformation of Ti-5553 alloy were investigated using Scanning Electron Microscopy /Transmission Electron Microscopy /crystallographic calculations. Results reveal that multiple-slip bands with two or three different propagating
\end{abstract}


directions would form during the warm compression. These three distinctly oriented

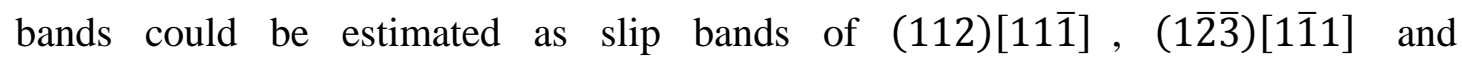
$(\overline{2} 13)[1 \overline{1} 1]$ types. Nano/ultrafine-trimorphic structure (lamellar $\alpha$, equiaxed $\alpha$ and irregular $\alpha$ ) formed dynamically during the warm deformation process due to the dynamic interplay between the initiation of the slip bands and the nucleation of $\alpha$ phase. There is an obvious competitive mechanism between dynamic recovery/dynamic recrystallization and $\alpha$ phase nucleation, which depended on the deformation parameters and modes. These results could provide valuable reference for process optimization and the microstructural evolution controlling.

Keywords: Titanium alloy; deformation mechanism; slip band; variants selection; orientation relationship, Ti-5553

\section{Introduction}

Metastable $\beta$ titanium alloys are important structural materials for aeronautical applications due to their high strength to density ratio, superior strength and ductility combination and good workability [1, 2, 3, 4]. Thereupon enormous work and effort in resolving the complex microstructural evolution related to thermomechanical process (TMP) and their correlations with the resultant mechanical properties have been done in the past decades $[5,6,7,8]$. Various alloy compositions and microstructures of titanium alloys are related to the different deformation mechanisms. The pure titanium (hexagonal close-packed structure, HCP) is mainly dominated by twining mechanism [9], while it has been reported that the deformation modes in the $\beta$ 
phase of titanium alloy include [10] (1) dislocation slip, (2) $\{332\}<113>$ twinning, (3) stress/strain-induced martensitic transformation. The actual deformation behavior of single $\beta$ phase of metastable $\beta$ titanium alloys strongly depends on the degree of stability of the $\beta$ phase [11]. However, this stability is associated with the extent of the $\beta$-stabilizing element. As the $\beta$ phase stability increases, the deformation mechanism gradually changes from stress-induced martensite to twinning and eventually to slip. In titanium alloys, the molybdenum equivalency ([Mo $\left.]_{\mathrm{eq}}\right)$ is defined as the amount of $\beta$-stabilizing element relative to the amount of molybdenum required for the same degree of $\beta$ phase stability, which is commonly a criterion to assess the stability of the $\beta$ phase in titanium alloys [12]. It is expressed with the equation as: $[\mathrm{Mo}]_{\mathrm{eq}}=\mathrm{Mo}+0.28 \mathrm{Nb}+0.22 \mathrm{Ta}+0.44 \mathrm{~W}+1.6 \mathrm{Cr}+1.54 \mathrm{Mn}+0.67 \mathrm{~V}+2.9 \mathrm{Fe}+1.25 \mathrm{Ni}+\ldots-\mathrm{Al}$

[13]. Necessarily, the dynamic recovery (DRV)/dynamic recrystallization (DRV) and fragmentation/globularization occurring during hot deformation should also be considered seriously.

Plastic deformation of crystals often occurs by slipping on only a few crystallographically equivalent planes [14]. The relative types of localized banded structures in the deformation zones are called slip bands. They appear in preferentially-oriented single crystals and grains in polycrystalline materials. Heidenreich [15] firstly observed the fine structure of slip bands on the surfaces of plastically deformed crystals. Until now, plenty of researchers $[16,17,18]$ have made a substantial contribution to this field, especially to finding the relationship between the slip bands and plastic deformation. In polycrystalline materials, the presence of 
plenty of oriented grains leads to a more complicated plastic deformation. Researches found that 'soft' oriented grains with high Schmid factor tend to deform plastically and form slip bands, but most of these results are obtained by theoretical calculations rather than experiments. Specifically, the slip mechanisms of titanium alloys with lamellar [19] and equiaxed [20] initial microstructures have been investigated. However, for the $\beta$ quenched initial microstructure, the form of slip bands accompanied by the precipitation of $\alpha$ phase would happen during the TMP. The nucleation behavior and the crystallographic characteristics of $\alpha$ phase in slip bands are not completely understood.

In addition to the changes of distribution and size of structure, TMP has a significant impact on the other aspects. For the $\alpha$ variants selection mechanism (VS) $[21,22,23,24]$ during the $\beta \rightarrow \alpha$ phase transformation, the deformation process can dominate it significantly besides the effects of the misorientation between two adjacent $\beta$ grains and the grain boundary plane [22]. R. Shi et, al. [25] developed a three-dimensional quantitative phase field model to predict variant selection and microstructural evolution in Ti-6Al-4V under the influence of both external and internal stresses. The results indicated that, for a given undercooling, the development of a transformation texture (also called microtexture) of the $\alpha$ phase due to variant selection during precipitation is determined by the interplay between externally applied stress or strain and internal stress generated by the precipitation reaction itself. Thus, the VS mechanism during TMP might be much more complicated and severely restricted by the nature of the defects such as grain boundaries, stacking faults, 
dislocations and slip bands [26, 27, 28, 29]. For instance, dislocations belonging to the $\{112\}<111>$ slip systems would favor the nucleation and growth of a single a variant whose orientation relationship is described by the components of the specific slip system [26, 27]. D. Qiu et, al. systematically elaborated the effects of low-angle grain boundaries (LAGBs) and dislocations on $\alpha$ phase morphology and variant selection mechanism through three-dimensional phase-field simulations [28, 29]. Moreover, the lattice defects introduced by deformation increase the number of nucleation sites and consequently raise the nucleation rate of the product phase. The morphology of precipitated $\alpha$ phase could be also changed during the hot deformation [30], even the orientation relationship between $\alpha / \beta$ phases (Burgers orientation relationship (BOR), i.e., $\left.\{0001\}_{\alpha} / /\{110\}_{\beta},\langle 11 \overline{2} 0\rangle_{\alpha} / /<111\right\rangle_{\beta}$ [31]) could be destroyed [32]. Because of these complications, limited work exists in the literature regarding the interplay between microstructure evolution and deformation defects. It is important to clarify the rules of $\alpha$ phase heterogeneous nucleation on defects for understanding the development of microstructure by diffusional phase transformation or precipitation reactions.

As discussed above, extensive studies of the microstructural evolution of titanium alloys related to TMP have been paid great attention. However, a clear understanding of the slip band formation during warm deformation accompanied by the dynamic precipitation of $\alpha$ phase in metastable $\beta$ titanium alloy is still not available. As a representative metastable $\beta$ titanium alloy, Ti-5Al-5Mo-5V-3Cr-0.5Fe (Ti-5553) is important in the aerospace industry applications due to its excellent combination of 
high yield strength, deep hardenability, fatigue and crack propagation properties as compared to the $\alpha+\beta$ titanium alloys $[2,3,4]$. The excellent mechanical properties of these alloys are attributed to the various sensitive microstructural compositions which are linked to a range of processing parameters, such as type of TMP, temperature, strain, strain rates and cooling rates. Thus, a systematic study was performed in present work on Ti-5553 alloy using transmission electron microscopy (TEM), scanning electron microscopy (SEM) and crystallographic calculations. The results could provide a valuable understanding and reference data for process optimization and the microstructural evolution control of metastable $\beta$ titanium alloy.

\section{Materials and research methodology}

The material used in the present study is $(\alpha+\beta)$ forged Ti-5553 bar with chemical composition (wt. \%) of Al: 5.26; Mo: 4.99; V: 4.80; Cr: 2.86; Fe: 0.42; Ti: balance. The $\beta$ transus temperature is approximately $870^{\circ} \mathrm{C}$. Cylindrical specimens, $10 \mathrm{~mm}$ in diameter and $15 \mathrm{~mm}$ in height, were machined from the forged bar. They were then solution treated at $900^{\circ} \mathrm{C}$ for $30 \mathrm{~min}$ followed by water quenching in order to obtain a single $\beta$ phase state with homogeneous microstructure. Uniaxial warm compression test was carried out with a Gleeble-3500 thermo-mechanical simulator along the cylindrical axis of the specimen. Prior to compression, each specimen was heated to the processing temperatures at a rate of $25^{\circ} \mathrm{C} / \mathrm{s}$ and then held for $10 \mathrm{~s}$ before the commencement of compression to ensure an establishment of homogeneous temperature field in the specimen. The temperature was controlled by a thermocouple welded to the central part of the specimen surface. Graphite lubrication was applied to 
the anvil and the specimen in order to reduce the relative friction between the two parts to enhance deformation homogeneity and also to prevent adhesion. The thermomechanical processing detailed parameters are shown in Table 1. After compression, all specimens were immediately cooled in water in order to retain the deformed microstructures. For comparison, specimens corresponding to all warm compression treatments were heat treated under exactly the same thermal conditions (heating, isothermal holding and cooling) just without deformation.

The deformed specimens were sectioned parallel to the compression axis and all microstructural and crystallographic characterizations were performed on this specimen section. For SEM (JSM-6500F) observations and EBSD measurements (OXFORD EBSD acquisition camera and the OXFORD-AZTEC online acquisition software), the specimens were first mechanically polished and then electro-polished with a solution of $20 \%$ perchloric acid in methanol under a voltage of $35 \mathrm{~V}$ at $10^{\circ} \mathrm{C}$ for 6s. The EBSD maps, grain boundaries with misorientations between $2^{\circ}$ and $15^{\circ}$ were defined as low-angle grain boundaries (LAGBs), and those of misorientation $>15^{\circ}$ as high-angle grain boundaries (HAGBs). In EBSD maps presented in this paper, black and green lines indicate HAGBs and LAGBs, respectively. And for the secondary electron images, the specimens were etched in a modified Kroll's reagent of 10 Vol.\% HF, 10 Vol.\% HNO3 and 80 Vol.\% H2O for 10s. For TEM (Philips CM200 operated at $200 \mathrm{kV}$ ) analyses, foil specimens were prepared firstly by mechanical thinning to about $80 \mu \mathrm{m}$ in thickness. Then discs with $3 \mathrm{~mm}$ in diameter were punched off and further thinned to be electron transparent by twin-jet electro-polishing using a Struers 
Tenupol-5 twin-jet electropolisher in a solution of $20 \%$ perchloric acid in methanol under $10 \mathrm{~V}$ at $-35^{\circ} \mathrm{C}$. Quantitative measurements were carried out using the Image-Pro-Plus analysis software [33]. The numerical calculations were programmed with the Matlab [34].

\section{Results and discussion}

\subsection{Initial microstructure of Ti-5553 alloy}

Materials used in this study were obtained from a $(\alpha+\beta)$ processed Ti-5553 billet, the forged microstructure is shown in Fig. 1(a)-(b). Apparently, the forged microstructure consists of globular or rod-like $\alpha$ phase particles, $\beta$ matrix and fine needle-like nano-scale $\alpha$ precipitations in the matrix. The single $\beta$ phase microstructure obtained by solution treatment at $900^{\circ} \mathrm{C}$ for $30 \mathrm{~min}$ followed by water quenching, as shown in Fig. 1(c), is composed of $\beta$ phase (Fig. 1(e)) with an average grain size of $\sim 300 \mu \mathrm{m}$ in equiaxed shape. Except for few low angle grain boundaries (LAGBs, $2^{\circ} \sim 15^{\circ}$ ), almost all of the $\beta$ grains are surrounded by high angle grain boundaries (HAGBs, >15 ${ }^{\circ}$ (Fig. 1(d)). The correlated misorientation angle distribution histogram in Fig. 1(f) displays that the initial microstructure possesses a disorientation angle distribution close to that of randomly oriented polycrystals (the line profile), suggesting that the alloy is not sharply textured.

\subsection{Slip band and its crystallographic characteristics}

Fig. 2 shows SEM images of the specimens isothermally compressed at $600^{\circ} \mathrm{C}$. Deformations were performed either at the same strain (0.7) but under two different 
strain rates $\left(0.01 \mathrm{~s}^{-1}\right.$ and $\left.0.001 \mathrm{~s}^{-1}\right)($ Fig. 2(a)-(b)) or at two different strains (0.7 and 1.2) but under the unique strain rate $\left(0.001 \mathrm{~s}^{-1}\right)$ (Fig. 2(b)-(c)). The two groups of deformations have three isothermal holding times: $1.2 \mathrm{~min}, 11.5 \mathrm{~min}$ and $20 \mathrm{~min}$, respectively. All the microstructures, as shown in Fig. 2, contain large amount of regularly spaced bands (highly contrasted) about 500nm in width. In certain grains, the bands appear with several orientations, forming a kind of reticular structure (Fig. 2(a2)). The morphology of the bands is deformation dependent. At higher strain rate, the bands are sharper and straighter (Fig. 2(a1)-(a2)) but with the decreasing strain rate, the bands become diffused and deviated (Fig. 2(c)-(d)). With increasing strain, the spacing of the bands turns out to be smaller and the number of bands increases (Fig. 2(c)). Moreover, these traces widen gradually with increasing strain and decreasing strain rate. Steps are formed at the intersections of the bands with the initial $\beta$ grain boundaries, as shown in Fig. 3, evidencing that the deformation is localized in the band areas. Thus, these slip bands can be considered as strain localization areas that accommodate the macroscopic deformation [35].

The slips systems were further identified by firstly calculating the Schmid Factors (SFs) of all possible slip systems of a body centered cubic (BCC) structure and their slip traces on the macroscopic sample surface, using the orientation of the $\beta$ phase, and then comparing them with the trace orientation of the observed bands. The possible slip systems sharing the same macroscopic trace on the surface of the sample are further discriminated using their SFs. The slips with higher SFs are considered as the ones with higher potential. 
The determination was done for the specimen deformed at higher strain rate $\left(0.01 \mathrm{~s}^{-1}\right)$ and with a lower strain $(0.7)$. The examined area is close to the upper surface of the cylindrical specimen (close to the anvil), where the strain is further reduced and the deformation bands are straight and sharp. As $\beta$ phase is not much deformed, especially in the areas between the bands, the orientation of the initial $\beta$ grains should not be too far from that before deformation. As the transformation progressed extremely rapidly, the $\beta$ grains are largely transformed to $\alpha$. In the areas between the bands, the $\beta$ lamellas are ultrafine $(<20 \mathrm{~nm}$ in width). It is impossible to obtain SEM/EBSD Kikuchi patterns to resolve the crystallographic orientation of $\beta$ matrix. Hence, the orientation of the $\beta$ phase was calculated indirectly from the measured orientations of the $\alpha$ variants under the determined BOR.

Fig. 4 displays a SEM image of the deformed microstructure and the examples of the two distinct $\alpha$ variants. Obviously, three sets of bands (band A, band B, and band C colored indicated in red, blue and green) can be observed in Fig. 4(a). For an unambiguous determination of the orientation of the parent phase, up to four distinct orientations of the product phase are needed [36]. However, this depends on the misorientation between the product phase variants. In the present case, $23 \alpha$ phase orientations in the same parent $\beta$ grains were measured manually to re-construct the $\beta$ matrix (Table 2). These 23 orientations correspond to the two variants that are

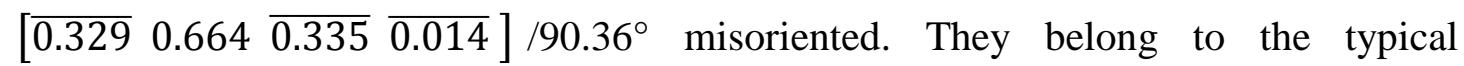
[1 $\overline{2.38} 1.380] / 90^{\circ} \alpha$ variants [37], although there is a small deviation. However, due to the deformations, orientations corresponding to the same variant may be $5^{\circ}$ appart. 
Using a clustering approach, we have selected for each variant the potential one parent which was the closest to the majority of that overall, meaning that it was possible to have a rough estimate of the parent orientation (within an uncertainity of about $8^{\circ}$.

As illustrated in Fig. 5, plane $P(h k l)_{\beta}$ of the $\beta$ phase is parallel to plane $P^{\prime}(h k l)_{\alpha}$ of the $\alpha$ phase. The direction $[u v w]_{\beta}$ in plane $P$ of $\beta$ phase is parallel to the direction $[u v w]_{\alpha}$ in plane $P^{\prime}$ of $\alpha$ phase. To derive the transformation matrix from the $\beta$ phase crystal reference frame to that of the $\alpha$ phase under the defined orientation relationship, an orthonormal coordinate system is needed that can be set based on OR parallel plane and the OR direction in either phase.

As shown in Fig. 5, the orthonormal reference frame is set in such a way that the basis vector $\mathrm{e}_{2}$ is parallel to the crystal direction $[u v w]_{\beta}$ and $[u v w]_{\alpha}$. The basis vector $\mathrm{e}_{3}$ is parallel to the normal direction of plane $P$ and $P^{\prime}\left(\mathrm{n}(h k l)_{\beta}\right.$ and $\left.\mathrm{n}(h k l)_{\alpha}\right)$. The axis $\mathrm{e}_{1}$ is parallel to the vector cross product of $[u v w]_{\beta}$ and $\mathrm{n}(h k l)_{\beta}$, and of $[u v w]_{\alpha}$ and $\mathrm{n}(h k l)_{\alpha}$. Under the given orientation relationship, the following relation holds:

$$
M_{E}^{\beta} S_{i}^{\beta} M_{C}^{\beta} T_{\beta}=M_{E}^{\alpha} S_{j}^{\alpha} M_{C}^{\alpha} T_{\alpha}
$$

Knowing the orientation of the $\alpha$ variants, the orientation of the $\beta$ phase with respect to the sample coordinate system expressed in matrix can be calculated with Eq.

$$
M_{E}^{\beta}=M_{E}^{\alpha} S_{j} M_{C}^{\alpha} T_{\alpha}\left(T_{\beta}\right)^{-1}\left(M_{C}^{\beta}\right)^{-1}\left(S_{i}\right)^{-1}=M_{E}^{\alpha} S_{j} M_{C}^{\alpha} T_{\alpha \rightarrow \beta}\left(M_{C}^{\beta}\right)^{-1}\left(S_{i}\right)^{-1}
$$


where, $M_{E}^{\alpha}$ is the Euler angle matrix of $\alpha$ phase, which can be determined by SEM-EBSD. $S_{i}$ and $S_{j}$ are the rotational symmetry elements of cubic crystal system ( $\beta$ ) and hexagonal crystal system $(\alpha)$, respectively. $T_{\alpha \rightarrow \beta}$ is the coordinate transformation matrix from $\alpha$ lattice basis to that of $\beta . T_{\beta}$ and $T_{\alpha}$ are the respective transformation matrix from the Bravais lattice basis of $\beta$ phase and $\alpha$ phase to the orthonormal OR reference system. $M_{C}^{\beta}$ and $M_{C}^{\alpha}$ are the transformation matrix from the orthonormal crystal coordinate system to the respective Bravais lattice basis of $\beta$ phase and $\alpha$ phase.

The $\{0001\}_{\alpha}$ and $\langle 11 \overline{2} 0\rangle_{\alpha}$ pole figures are displayed in Fig. 6(a). The calculated $\beta$ orientations represented with their $\{110\}_{\beta}$ and $\langle 1 \overline{1} 0\rangle_{\beta}$ pole figures are given in Fig. 6(b). It can be seen that the calculated $\beta$ orientations form a kind of orientation "cloud" with some distribution but not very large, as the case of the $23 \alpha$ variants in Fig. 6(a). From this orientation "cloud", the average orientation is calculated and taken as the initial orientation of the $\beta$ grain. The Euler angles of the average $\beta$ orientation with respect to the sample coordinate system are $\left(179.39^{\circ}\right.$, $\left.80.72^{\circ}, 335.06^{\circ}\right)$

Using the determined orientation of the $\beta$ phase, the possible slip systems were further analyzed. For BCC metals, the most energetically favorable slip direction is $\langle 111\rangle$. The $\langle 111\rangle$ slips can be realized on six $\{110\}$ planes, twelve $\{112\}$ planes and twenty four $\{123\}$ planes. Based on such an assumption, the orientations of the three families of crystal planes with respect to the sample coordination system are calculated and displayed as the respective plane pole figures in Fig. 7, where the SFs 
of the corresponding slip systems are also indicated. Comparing the slip plane traces and taking into account of the value of the SFs, the three distinctly oriented bands A, $\mathrm{B}$ and $\mathrm{C}$ could be estimated as slip bands of (112)[11 $\overline{1}],(1 \overline{2} \overline{3})[1 \overline{1} 1]$ and ( 213$)[1 \overline{1} 1]$ types. Thereupon, the stereoscopic crystallographic schematic can be constructed in the Fig. 8.

\subsection{Warm deformation mechanism of metastable $\beta$ titanium alloys}

\subsubsection{Slip, DRV/DRX and globularization}

Compared with the results of high temperature deformation at $800^{\circ} \mathrm{C}$ in Ref. [38], there is no significant change in the deformation mechanism of Ti-5553 alloy. Well-defined thin slip lines in high temperature deformation are replaced by slip bands at low temperature deformation. The $\beta$ grains are sheared relative to each other by the generation, movement, and rearrangement of dislocation in most titanium alloys upon hot deformation. Thus, each $\beta$ grain might possess its own set of dislocations on the preferred slip planes that are distinctly oriented as compared to the adjacent grains (Fig. 3). That is consistent with the fact that the multiple- or cross-slips in BCC metal can appear easily due to the high stacking fault energy. However, no cracks initiated along the bands or at the intersection sites between the slip bands and the grain boundaries, which implies excellent workability of Ti-5553 alloy [39].

The actual deformation behavior of titanium alloys strongly depends on the degree of stability of the $\beta$ phase, especially at room temperature [11]. The $\beta$ phase stability 
increases, and the deformation mode at room temperature gradually changes from stress-induced martensite to twinning and eventually to slip. [1]. The $\beta$ phase has a close to critical $[\mathrm{Mo}]_{\mathrm{eq}}$ of 9.6 in Ti-5553 alloy, which can be attributed to the fact that the addition of enough $\beta$-stabilizing elements inhibits the formation of stress-induced martensite and twins [11]. Furthermore, the dislocation slip systems are controlled by thermally-activated process. That is why dislocation slip is the predominant hot deformation mode in metastable $\beta$ titanium alloys, whether deformation at the high temperature (for example $800^{\circ} \mathrm{C}[38]$ ) and lower $600^{\circ} \mathrm{C}$ ) or room temperature. The slip as a predominant deformation mechanism was also observed in other Ti-alloys by S. Hanada et al. [40]. Although people observed deformation induced $\alpha / \alpha \% / \omega /$ twin closer to room temperature conditions occasionally [41, 42], dislocation slip still dominates the process. Besides, it is generally accepted that the predominating softening mechanism of metastable $\beta$ titanium alloys in high temperature range is DRV [3], accompanied by some degree of DRX. The DRX could be identified as typical continuous dynamic recrystallization (CDRX), which involves a transformation of low angle boundaries into high angle boundaries of the subgrains $[43,44]$. Furthermore, for titanium alloy materials, there is also a common deformation mechanism operating almost in the entire deformation temperature range, which is the fragmentation and globularization of the microstructure. It should also be noted that the fragmentation and globularization of $\alpha / \beta$ microstructure are related to the loading direction [45] and detailed deformation parameters [46]. According to the 
discussion above, the deformation mechanisms in metastable $\beta$ titanium alloy related to temperature are shown in Fig. 9.

\subsubsection{Deformation induced phase transformation}

The amount of $\alpha$ precipitates quantified in the warm compressed specimens and their heat treated counterparts is displayed in Fig. 10(a). It can be seen from the figure that the amount of $\alpha$ phase is significantly different between the deformed specimen to 0.7 at $0.01 \mathrm{~s}^{-1}$ and the aged specimen (1.2min), about $41 \%$ and about $1.5 \%$ respectively. This indicates that the deformation promotes the phase transformation due to the much more crystallographic defects as the precipitates nucleation sites [30]. However, with the increase of the holding time for both the deformed and the aged specimens, the difference is greatly reduced from about $45 \%$ (deformed, 0.7 at $0.001 \mathrm{~s}^{-1}$ ) versus about $52 \%$ (aged, $11.5 \mathrm{~min}$ ) to about $54 \%$ (deformed, 1.2 at $0.001 \mathrm{~s}^{-1}$ ) versus about 53\% (aged, 20min). This means that with the progress of the transformation, the equilibrium amount of transformation is reached in both deformation and ageing conditions. In this context, the deformation can significantly affect the transformation kinetics, but has little effect on the phase equilibrium.

The effects of deformation on the extents of $\beta \rightarrow \alpha$ transformation are completely different between high $\left(800^{\circ} \mathrm{C}\right)$ and low $\left(600^{\circ} \mathrm{C}\right)$ temperature deformation processes by comparing the corresponding area fraction of $\alpha$ phase (Fig. 10). Actually, the two transformation processes, DRV/DRX and $\beta \rightarrow \alpha$ transformation, occurred competitively during almost the whole hot compression (Fig. 11(a)). Although the 
Gibbs free energy change $(\Delta G)$ is increased due to the introduction of the stored energy $\Delta G_{d}$ provided by deformation, it is not clear which one consumes the increased system energy preferentially. Both of these two processes are diffusive in nature, but the efforts required them to happen are not the same. As the Fig. 11(a) shows, there should be a transit temperature $\left(T_{\text {trans }}\right)$ above which the energy barrier for DRV/DRX is smaller and thereupon the dynamic softening is prevalent and $\beta \rightarrow \alpha$ phase transformation becomes inhibited. Conversely, the energy barrier for phase transformation under the low temperature is much smaller than DRV/DRX, thus the DRV/DRX is suppressed and $\beta \rightarrow \alpha$ phase transformation is promoted. Fundamentally, the kinetics of $\beta \rightarrow \alpha$ phase transformation is significantly changed by the application of deformation, as the TTT schematic diagram Fig. 11(b) shows.

\subsection{Dynamic precipitation of nano/ultrafine $\alpha$ phase and orientation relationship}

Examinations at higher magnification revealed that the slip band areas in all the deformed specimens are composed of equiaxed constituents (around 50 200nm in diameter), whereas the areas between the bands consist of lamellar constituents (about $20 \mathrm{~nm}$ in width) and minority of irregular fragmentized structures (about 20nm in width). Thereupon the nano/ultrafine-trimorphic structure is formed during the warm deformation process $\left(600^{\circ} \mathrm{C}\right)$, as shown in Fig. 12. These three constituents coarsen with the increasing deformation time, represented by decreasing strain rate at constant strain or by increasing strain at constant strain rate. What needs to be stressed is that all of the various $\alpha$ phase precipitated dynamically during the compression tests. 
For comparison, the SEM micrographs of three specimens aged at $600^{\circ} \mathrm{C}$ with the same isothermal holding time corresponding to the warm deformation processes (1.2min, 11.5min and 20min corresponding to the Fig. 2(a)(b)(c) respectively) are shown in Fig. 13. It shows that $\alpha$ phase only forms continuously along $\beta$ grain boundaries $\left(\alpha_{\mathrm{GB}}\right)$ when held for 1.2min, (Fig. 13(a)). When the specimens were held for $11.5 \mathrm{~min}$ and $20 \mathrm{~min}$, respectively, large amount of plate-like $\alpha$ phase forms in the interiors of $\beta$ grains (intragranular $\alpha, \alpha_{\mathrm{I}}$ ) and in the vicinities of $\beta$ grain boundaries (Widmanstätten $\alpha, \alpha_{\mathrm{WGB}}$ ) (Fig. 13(b)-(c)). Although these three $\alpha$ constituents are typical for Ti-5553 alloy when aged at $600^{\circ} \mathrm{C}$, such microstructures are exceedingly different from the aforementioned deformed microstructures.

Further TEM micrographs and SAED patterns are shown in Fig. 14. The SAED pattern of the fine equiaxed microstructure shows that the $\alpha / \beta$ reflections tend to form arcs, suggesting the randomization of the crystallographic orientations of the two phases (Fig. 14(a)). Obviously, the BOR between $\alpha$ and $\beta$ phases have been destroyed gradually during the deformation process. Whereas, compared with the case of heat treatment process [24], all the $\alpha$ phase $\left(\alpha_{\mathrm{GB}}\right.$ and $\left.\alpha_{\mathrm{I}}\right)$ generally maintains the BOR with the $\beta$ matrix. The external warm deformation has a significant influence on the obeying of BOR during $\beta \rightarrow \alpha$ phase transformation. For the lamellar constituents, they are composed of alternatively distributed $\alpha$ and $\beta$ platelets, maintaining BOR $\left(\{0001\}_{\alpha}\left\|\{110\}_{\beta},\langle 11 \overline{2} 0\rangle_{\alpha}\right\|\langle 111\rangle_{\beta}\right)$, as shown in Fig. 14(b). The SAED pattern indicates that the $\alpha$ lamellae in one colony possesses the unique crystallographic orientation, which also means the strong $\alpha$ variant selection has taken place. 
According to the above SEM/TEM observations of the deformed microstructure, the detailed dynamic evolution process under the warm compression can now be better understood. Because the initiation of the slip bands produced by dense dislocations is accompanied by the nucleation of $\alpha$ phase during the warm deformation, the slip bands would be the preferential nucleation sites. Abundant cumulate dislocations and the drastic lattice rotation in the bands would result in $\alpha$ nuclei growing up to a fine equiaxed structure, as Fig. 14(a) shows. These precipitates underwent a continuous rotation and increased misorientations to accommodate the continuous strain. On the other hand, the $\alpha$ platelets with certain stretching directions are favorable for nucleation and growth due to the variant selection under the applied force, as Fig. 14(b) shows. When lower compression strain is applied, severe kinking of $\alpha / \beta$ lamellae occurred in the $\alpha / \beta$ lamellar colonies under the complicated shear stress state. And then, globularization (fragmentation) of the $\alpha / \beta$ lamellae may occur under the effect of dense dislocation configurations with the increasing strain. When higher compression strain is applied, slip bands might form directly and across $\alpha / \beta$ lamellae gradually. Thereupon there is a critical value $\left(\sigma_{\mathrm{c}}\right)$ during deformation process used to divide the kinking and fragmentation of $\alpha / \beta$ lamellar structure. The typical microstructure evolution during the plastic forming process can significantly affect the flow softening behavior of alloys. Therefore, the analysis of the microstructure evolution characteristics of the alloy material with the lamellar structure during the deformation process should be seriously considered.

\section{Conclusions}


The formation of slip bands and microstructure evolution (morphology, distribution and variant selection mechanism of $\alpha$ phase precipitated dynamically) during the warm deformation were investigated in the Ti-5553 metastable $\beta$ titanium alloy with single $\beta$ phase initial microstructure, using the SEM, TEM and crystallographic calculations. The deformation mechanisms were analyzed and discussed in detail. The following conclusions can be drawn:

(1) Dislocation slip is a leading deformation mechanism for the Ti-5553 alloy, accompanying by a degree of fragmentation of $\alpha$ phase. Single or multiple-slip bands with two or three different propagating directions form during the warm deformation process. The slip bands are straighter and clearer for the higher strain rate deformation process. Moreover, the bands widen gradually with the increasing strain and decreasing strain rate.

(2) Slip in the $\beta$ phase of the Ti-5553 alloy occurs predominantly on the $\{112\}$ and $\{123\}<111>$ slip systems. Comparing the slip plane traces and taking into account of the values of the SFs, the three distinctly oriented bands are slip bands (112)[11 $\overline{1}],(1 \overline{2} \overline{3})[1 \overline{1} 1]$ and $(\overline{2} 13)[1 \overline{1} 1]$ respectively.

(3) Deformation induced phase transformation promotion of $\beta \rightarrow \alpha$ process proceed during the warm deformation due to the higher number of induced deformation defects acting as the $\alpha$ phase nucleation sites and accelerated growth of $\alpha$ precipitates and retarded recovery/recrystallization. There is a competitive mechanism between DRV/DRX and $\alpha$ phase nucleation, and the specific 
performance depends on the deformation parameters and modes.

(4) Big differences could be found between the microstructures of warm compression and heat treatment specimens. A large amount of $\alpha$ phase with three different morphologie (lamellar $\alpha$, equiaxed $\alpha$ and irregular $\alpha$ ) precipitate dynamically during the warm deformation process, forming the nano/ultrafine-trimorphic structure. In the core region of the slip bands, equiaxed $\alpha / \beta$ grains, $50 \sim 200 \mathrm{~nm}$ in grain size, are present without BOR. However, lamellar $\alpha$ and $\beta$ phases between the band regions, $\sim 20 \mathrm{~nm}$ in width and with strict BOR, are arranged alternately and orderly.

\section{Acknowledgements}

This work was supported by Natural Science Basic Research Plan in Shaanxi Province of China (2018JQ5035 ), Major State Research Development Program of China (2016YFB0701305) and Shaanxi Science \& Technology Co-ordination \& Innovation Project (2016KTZDCY-01-03). Jiangkun Fan also thanks the Fundamental Research Funds for the Central Universities (G2017KY0310).

\section{Appendix}

For $\beta$ phase, $a=b=c, \alpha=\beta=\gamma=90^{\circ}$, thus the coordinate transformation matrix from the orthonormal crystal coordinate system to the lattice basis is

$$
M_{C}^{\beta}=\left[\begin{array}{lll}
a & 0 & 0 \\
0 & a & 0 \\
0 & 0 & a
\end{array}\right]
$$

For $\alpha$ phase, $a=b \neq c, \alpha=\beta=90^{\circ}, \gamma=120^{\circ}$, the coordinate transformation is 


$$
M_{C}^{\alpha}=\left[\begin{array}{ccc}
\frac{\sqrt{3}}{2} a & 0 & 0 \\
-\frac{1}{2} a & a & 0 \\
0 & 0 & { }_{c}
\end{array}\right]
$$

$T_{\alpha \rightarrow \beta}$ is the coordinate transformation matrix from $\alpha$ lattice basis to that of $\beta$. Its calculation process is more complicated, simple expression is $T_{\alpha \rightarrow \beta}=T_{\alpha}\left(T_{\beta}\right)^{-1} \cdot T_{\beta}$ and $T_{\alpha}$ are the respective transformation matrix from the Bravais lattice basis of $\beta$ phase and $\alpha$ phase to the orthonormal OR reference system, as shown below.

$$
T_{\beta}=[-1 /(\operatorname{sqrt}(6)), 1 /(\operatorname{sqrt}(3)), 1 /(\operatorname{sqrt}(2)) ; 1 /(\operatorname{sqrt}(6)),-1 /(\operatorname{sqrt}(3)), 1 /(\operatorname{sqrt}(2)) ; 2 /(\operatorname{sqrt}(6)
$$

$$
), 1 /(\operatorname{sqrt}(3)), 0]
$$

$$
T_{\alpha}=\left[\mathbf{e}_{1} 11, \mathbf{e}_{1} 12, \mathbf{e}_{1} 13 ; \mathbf{e}_{2} 21, \mathbf{e}_{2} 22, \mathbf{e}_{2} 23 ; \mathbf{e}_{3} 31, \mathbf{e}_{3} 32, \mathbf{e}_{3} 33\right]
$$

When establishing three axes based on the BOR, the basis vector $\boldsymbol{e}_{\mathbf{2}}$ is parallel to the crystal direction $[1,1,1]_{\beta}$ and $[1,1,-2,0]_{\alpha}$. The basis vector $\boldsymbol{e}_{3}$ is parallel to the normal direction of plane $(1,1,0)_{\beta}$ and $(0,0,0,1)_{\alpha}$. The axis $\boldsymbol{e}_{\mathbf{1}}$ is parallel to the vector cross product of $[1,1,1]_{\beta}$ and $(1,1,0)_{\beta}$, and of $[1,1,-2,0]_{\alpha}$ and $(0,0,0,1)_{\alpha}$.

\section{Author contributions}

Jiangkun Fan, Yudong Zhang and Hongchao Kou conceived experiments and wrote the paper. Jiangkun Fan, Yudong Zhang and Lionel Germain performed experiments and data analysis. Ke Hua and Luyao Tang assisted in standoff experimental set-up and analysis. Claude Esling and Jinshan Li assisted in data analysis. All authors have given their approval to the final version of the manuscript.

\section{References}


[1] D. Banerjee, J. C. Williams, Acta Materialia 61 (2013) 844-879.

[2] R. Boyer, R. D. Briggs, J. Mater. Eng. Perform. 14 (2005) 681-685.

[3] M. Jackson, R. Dashwood, L. Christodoulou, H. M. Flower, Metall. Mater. Trans. A 36 (2005) 1317-1327.

[4] S. L. Raghunathan, A. M. Stapleton, R. J. Dashwood, M. Jackson, D. Dye, Acta Mater. 55 (2007) 6861-6872.

[5] A. Zafari, X. S. Wei, W. Xu, K. Xia, Acta Materialia 97 (2015) 146-155.

[6] D. Choudhuri, Y. Zheng, T. Alam, R. Shi, M. Hendrickson, S. Banerjee, R. Banerjee, Acta Materialia 130 (2017) 215-228.

[7] J. K. Fan, J. S. Li, Y. D. Zhang, H. C. Kou, J. Ghanbaja, W. M. Gan, L. Germain, C. Esling, Journal of Applied Crystallography 50 (2017) 795-804.

[8] T. Liu, L. Germain, J. Teixeira, E. Aeby-Gautier, N. Gey, Acta Materialia 141 (2017) 97-108.

[9] S. Xu, M. Gong, C. Schuman, J. S. Lecomte, X. Xie, J. Wang, Acta Materialia 132 (2017) 57-68.

[10]T. Grosdidier, C. Roubaud, M.J. Philippe, and Y. Combres, Scripta Mater. 36 (1997) 21-28.

[11]Z. Wyatt, S. Ankem, J. Mater. Sci. 45 (2010) 5022-5031. 
[12]W. Xu, K. B. Kim, J. Das, M. Calin, J. Eckert, Scripta Mater. 54 (2006) 19431948.

[13]S. Fujishiro, D. Eylon, T. Kishi. Metallurgy and technology of practical titanium alloys. TMS Warrendale, PA, 1994, 31-32.

[14] J. C.Fisher, E. W. Hart, R. H. Pry, Phys. Rev. 87 (1952) 958-69.

[15]R. D. Heidenreich, W. Shockley, J. Appl. Phys. 18 (1947) 1029-31.

[16]J. Kumar, V. Singh, P. Ghosal, V. Kumar, Materials Science and Engineering: A 623 (2015) 49-58.

[17]M. Wan, Y. Zhao, W. Zeng, G. Cai, Journal of Alloys and Compounds 619 (2015) $383-388$.

[18]I. G. Dastidar, V. Khademi, T. R. Bieler, A. L. Pilchak, M. A. Crimp, C. J. Boehlert, Mater. Sci. Eng. A. 636 (2015) 289-300.

[19] M. F. Savage, J. Tatalovich, M. J. Mills, Philos. Mag. 84 (2004) 1127-1154.

[20] J. R. Seal, M. A. Crimp, T. R. Bieler, C. J. Boehlert, Materials Science \& Engineering A 552 (2012) 61-68.

[21]R. Shi, V. Dixit, H. L. Fraser, Y. Wang, Acta Materialia 75 (2014) 156-166.

[22]R. Shi, V. Dixit, G. B. Viswanathan, H. L. Fraser, Y. Wang, Acta Materialia 102 (2016) 197-211. 
[23] G. C. Obasi, S. Birosca, D. L. Prakash, J. Q. da Fonseca, M. Preuss, Acta Materialia 60 (2012) 6013-6024.

[24]M. Salib, J. Teixeira, L. Germain, E. Lamielle, N. Gey, E. Aeby-Gautier, Acta Materialia 61 (2013) 3758-3768.

[25]R. Shi, Y Wang, Acta Materialia, 61 (2013) 6006-6024.

[26]T. Furuhara, S. Takagi, H. Watanabe, T. Maki, Metall. Mater. Trans. A. 27 (1996) $1635-1646$.

[27] T. Furuhara, T. Maki, Materials Science and Engineering: A 312 (2001) 145-154.

[28]D. Qiu, R. Shi, D. Zhang, W. Lu, Y. Wang, Acta Materialia, 88 (2015) 218-231.

[29]D. Qiu, R. Shi, P. Zhao, D. Zhang, W. Lu, Y. Wang, Acta Materialia, 112 (2016) $347-360$.

[30] A. Dehghan-Manshadi, R. J. Dippenaar, Mater. Sci. Eng. A. 552 (2012) 451-456.

[31]W. G. Burgers, Physica. 1 (1934) 561-586.

[32]M. Klimova, S. Zherebtsov, G. Salishchev, S. L. Semiatin, Mater. Sci. Eng. A. 645 (2015) 292-297.

[33] http://www.mediacy.com.cn/cn/index/index.asp.

[34] http://www.mathworks.com/products.

[35] J. K. Fan, Université de Lorraine. (2016) 83-98.

[36]L. Germain, N. Gey, M. Humbert, Ultramicroscopy 107 (2007) 1129-1135. 
[37] S. C. Wang, M. Aindow, M. J. Starink, Acta Materialia, 51(9) (2003) 2485-2503.

[38] J. K. Fan, J. S. Li, Y. D. Zhang, H. C. Kou, L. Germain, N. Siredey-Schwaller, C. Esling, Advanced Engineering Materials 19 (2017) 1600859.

[39] J. K. Fan, H. C. Kou, M. J. Lai, B. Tang, H. Chang, J. S. Li, Mater. Design. 49 (2013) 945-952.

[40]S. Hanada, O. Izumi, Metallurgical Transactions A 18 (1987) 265-271.

[41]S. Neelakantan, E. I. Galindo-Nava, D. San Martin, J. Chao, P. E. J. Rivera-Díaz-del-Castillo, Materials Science and Engineering: A 590 (2014) 140146.

[42]A. Zafari, Y. Ding, J. Cui, K. Xia, Metallurgical and Materials Transactions A 47 (2016) 3633-3648.

[43] J. K. Fan, H. C. Kou, M. J. Lai, B. Tang, H. Chang, J. S. Li, Mater. Sci. Eng. A. 84 (2013) 121-132.

[44] S. Gourdet, F. Montheillet, Acta Mater. 51 (2003) 2685-2699.

[45]L. Germain, N. Gey, M. Humbert, P. Bocher, M. Jahazi, Acta Mater. 53 (2005) $3535-3543$.

[46] S. Zherebtsov, M. Murzinova, G. Salishchev, S. L. Semiatin, Acta Mater. 59 (2011) 4138-4150. 


\section{Figure captions}

Fig. 1 Initial microstructure of Ti-5553 alloy: (a)(b) SEM images of As-forged alloy;

(c) band contrast micrograph of Ti-5553 alloy after solution treatment (holding at $900^{\circ} \mathrm{C}$ for 30 minutes and quenching in water); (d) GB-IPF-EBSD map of solution microstructure; (e) XRD pattern of solution microstructure; (f) corresponding histogram of correlated disorientation angle distribution in solution microstructure.

Fig. 2 SEM images of Ti-5553 warm compressed at $600^{\circ} \mathrm{C}$ to (a) 0.7 under $0.01 \mathrm{~s}^{-1}$, (b) 0.7 under $0.001 \mathrm{~s}^{-1}$ and (c) 1.2 under $0.001 \mathrm{~s}^{-1}$.

Fig. 3 SEM images of the specimen warm compressed at $600^{\circ} \mathrm{C}$ to 0.7 at $0.01 \mathrm{~s}^{-1}$. (a) Steps formed at the intersections of the bands with the initial $\beta$ boundary and (b) a zoomed micrograph of the area outlined by the dashed box in (a).

Fig. 4 (a) SEM images of Ti-5553 deformed at $600^{\circ} \mathrm{C}$ to 0.7 at $0.01 \mathrm{~s}^{-1}$ (b) Kikuchi line patterns of two distinct variants and their Euler angles. Three distinctly oriented bands are outlined in red (band A), blue (band B) and green (band C) and their inclination angles with respect to the horizontal axis are indicated with the white dashed line.

Fig. 5 Schematic illustration of the orientation relationship (OR) between $\beta$ and $\alpha$.

Fig. 6 (a) $\{0001\}_{\alpha}$ and $\langle 11 \overline{2} 0\rangle_{\alpha}$ pole figures of the $23 \alpha$ randomly selected in the area shown in Fig. 4(a) and (b) $\{110\}_{\beta} /\langle 1 \overline{1} 0\rangle_{\beta}$ Pole figures of the $\beta$ orientations calculated from the 23 experimental $\alpha$ orientations under BOR. 
Fig. 7 (a) SEM images of Ti-5553 deformed at $600^{\circ} \mathrm{C}$ to 0.7 at $0.01 \mathrm{~s}^{-1}$ (b) $\{110\},\{112\}$ and $\{123\}$ pole figures of the $\beta$ in (a). The SF values under the compression are indicated for each slip system. The slips systems correspond to the three distinctly oriented bands are circled in red, blue and green.

Fig. 8 The crystallographic schematic of the multiple-slip systems in the single $\beta$ grain (Euler angles, $\left(179.39^{\circ}, 80.72^{\circ}, 335.06^{\circ}\right)$ ) with respect to the compressive loading.

Fig. 9 Schematic diagram of deformation mechanisms of titanium alloy related to temperature.

Fig. 10 Area fractions of $\alpha$ phase in the hot compressed and the corresponding heat treated specimens: (a) $600 \square$; (b) $800 \square$ [34].

Fig. 11 (a) Illustration of the completion between DRV/DRX and phase transformation; (b) TTT schematic diagram under the heat treatment and thermo-mechanical conditions.

Fig. 12 SEM images of the nano/ultrafine-trimorphic structure in the central area of the deformed Ti-5553 alloy at $600{ }^{\circ} \mathrm{C}, 0.001 \mathrm{~s}^{-1}, 0.7$ : (a) equiaxed $\alpha$; (b) lamellar $\alpha$; (c) irregular $\alpha$.

Fig. 13 SEM images of the Ti-5553 aged at $600^{\circ} \mathrm{C}$ for (a) $1.2 \mathrm{~min}$, (b) $11.5 \mathrm{~min}$ and (c) $20 \mathrm{~min}$.

Fig. 14 TEM micrographs and SAED patterns of warm compressed Ti-5553 at $600^{\circ} \mathrm{C}$ to 0.7 at $0.001 \mathrm{~s}^{-1}$ : (a) bright field images and the SAED pattern of fine equiaxed microstructure and (b) bright field and dark field images and the SAED patterns of the 
lamellar microstructure. 


\section{Table captions}

Table 1 Detailed thermomechanical processing parameters.

Table 2 Sets of Euler angles of $\alpha$ phase in local region of unique $\beta$ matrix. 
Table 1 Detailed thermomechanical processing parameters.

\begin{tabular}{ccc}
\hline Temperature $\left({ }^{\circ} \mathrm{C}\right)$ & Strain rate $\left(\mathrm{s}^{-1}\right)$ & Strain \\
\hline 600 & 0.001 & 0.7 \\
600 & 0.01 & 0.7 \\
600 & 0.001 & 1.2 \\
\hline
\end{tabular}


Table 2 Sets of Euler angles of $\alpha$ phase in local region of unique $\beta$ matrix

\begin{tabular}{cccccccc}
\hline No. & $\varphi 1$ & $\Phi$ & $\varphi 2$ & No. & $\varphi 1$ & $\Phi$ & $\varphi 2$ \\
\hline 1 & 66.88281 & 22.55277 & 49.88193 & 13 & 63.68449 & 22.00545 & 55.60367 \\
2 & 88.70051 & 110.7349 & 36.96032 & 14 & 93.39682 & 107.2791 & 35.88599 \\
3 & 67.68484 & 22.5097 & 48.20908 & 15 & 74.60153 & 19.26287 & 45.87702 \\
4 & 91.1031 & 111.0795 & 38.47552 & 16 & 65.32433 & 20.89918 & 57.7801 \\
5 & 60.72276 & 20.98019 & 55.10453 & 17 & 60.36485 & 22.01691 & 1.430637 \\
6 & 66.42749 & 22.25093 & 50.3376 & 18 & 94.92178 & 110.9403 & 35.79478 \\
7 & 65.57208 & 22.09155 & 51.32633 & 19 & 94.07244 & 109.1879 & 37.75416 \\
8 & 90.74396 & 111.4079 & 39.95787 & 20 & 73.3438 & 21.67609 & 43.2484 \\
9 & 62.57056 & 23.77268 & 55.63908 & 21 & 89.37614 & 109.8079 & 35.40767 \\
10 & 64.96496 & 22.9135 & 51.52016 & 22 & 72.50777 & 22.16612 & 43.62157 \\
11 & 91.05508 & 108.6209 & 38.77714 & 23 & 71.7724 & 22.7696 & 45.26417 \\
12 & 63.37646 & 19.96013 & 55.61627 & $/$ & $/$ & $/$ & $/$ \\
\hline
\end{tabular}


(a)

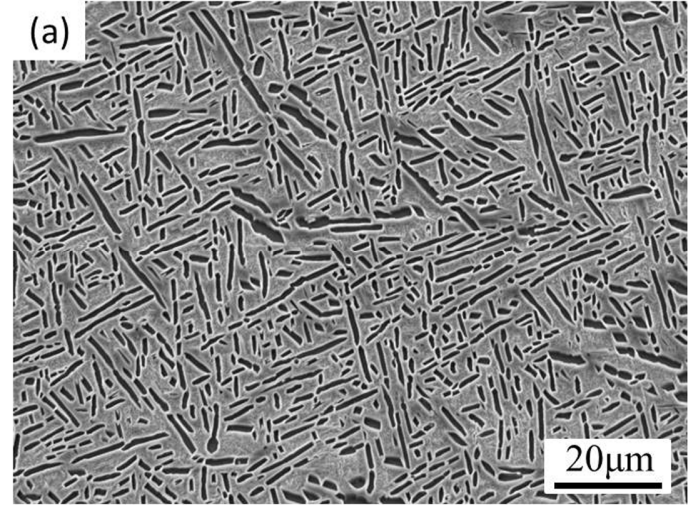

(c)
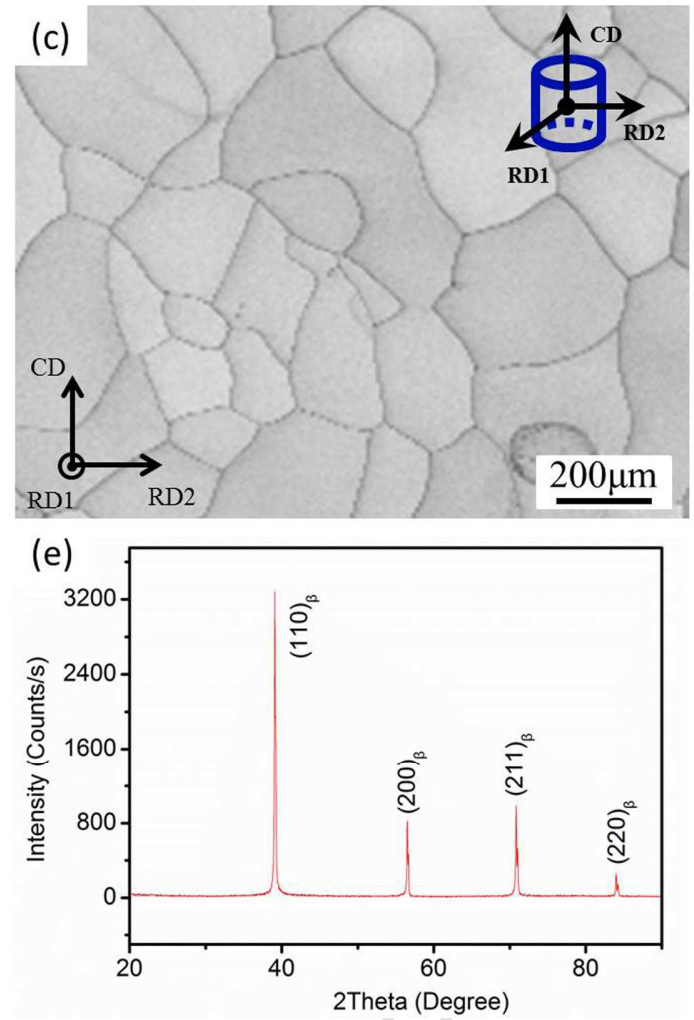
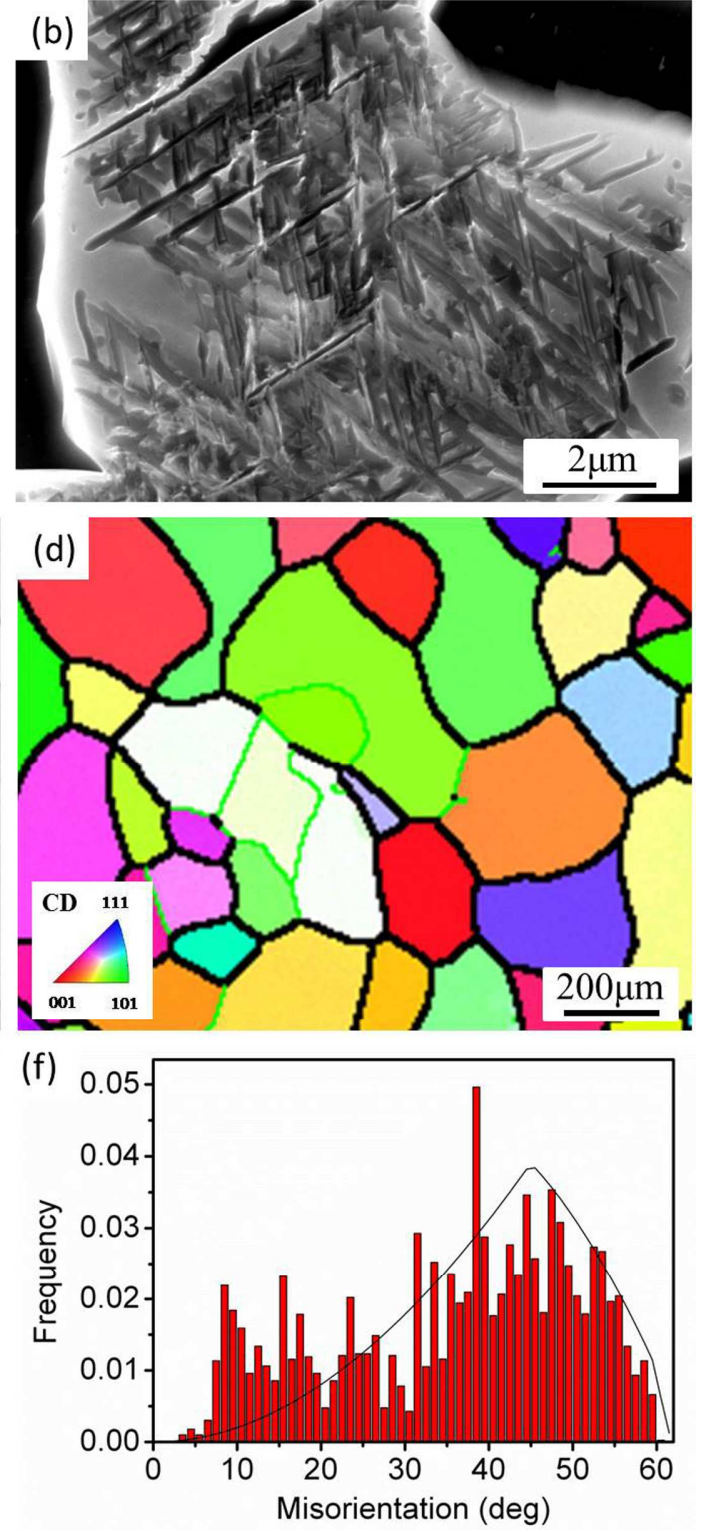

Fig. 1 Initial microstructure of Ti-5553 alloy: (a)(b) SEM images of As-forged alloy;

(c) band contrast micrograph of Ti-5553 alloy after solution treatment (holding at

$900^{\circ} \mathrm{C}$ for 30 minutes and quenching in water); (d) GB-IPF-EBSD map of solution

microstructure; (e) XRD pattern of solution microstructure; (f) corresponding histogram of correlated disorientation angle distribution in solution microstructure. 
(a)

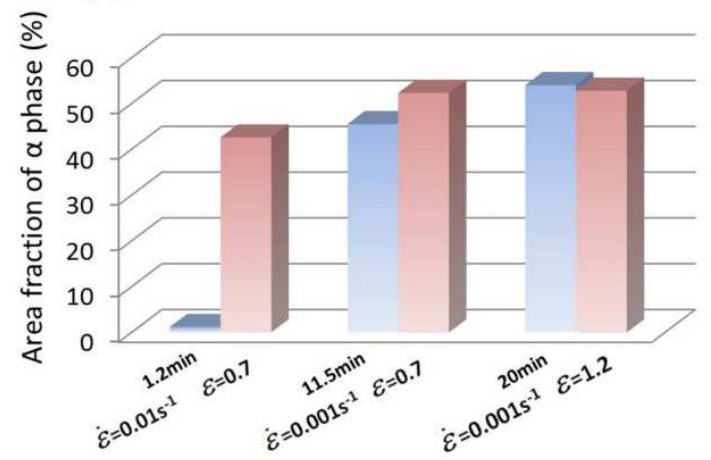

(b)

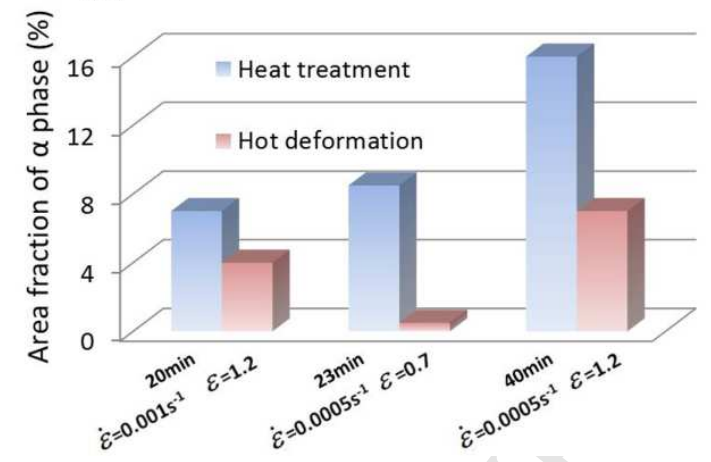

Fig. 10 Area fractions of $\alpha$ phase in the hot compressed and the corresponding heat treated specimens: (a) $600 \square$; (b) $800 \square$ [34]. 


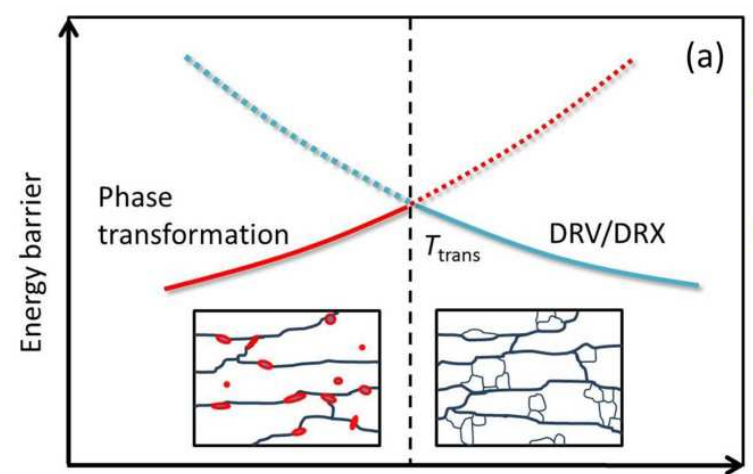

Deformation temperature

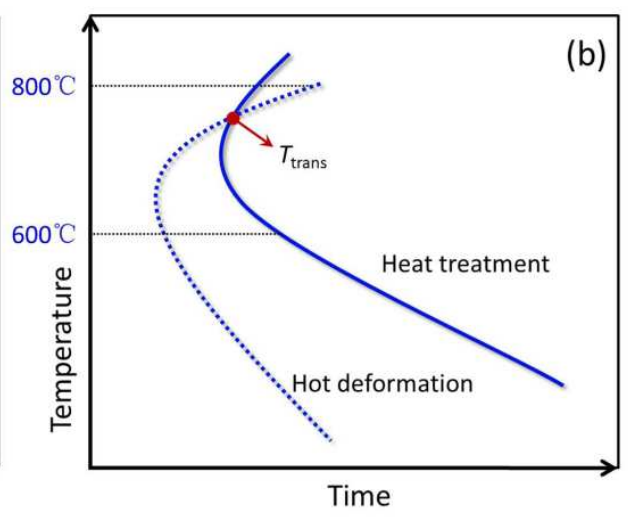

Fig. 11 (a) Illustration of the completion between DRV/DRX and phase transformation; (b) TTT schematic diagram under the heat treatment and thermo-mechanical conditions. 

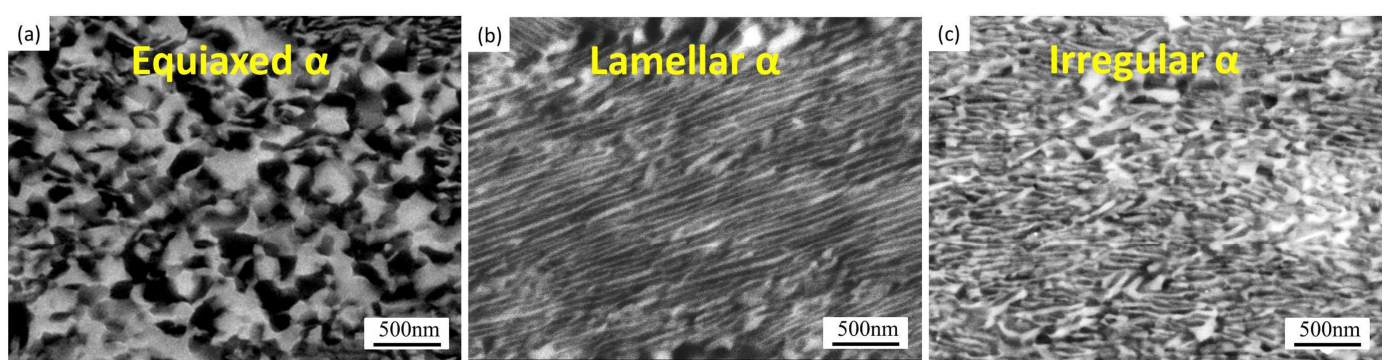

Fig. 12 SEM images of the nano/ultrafine-trimorphic structure in the central area of

the deformed Ti-5553 alloy at $600^{\circ} \mathrm{C}, 0.001 \mathrm{~s}^{-1}, 0.7$ : (a) equiaxed $\alpha$; (b) lamellar $\alpha$; (c) irregular $\alpha$. 
(a)

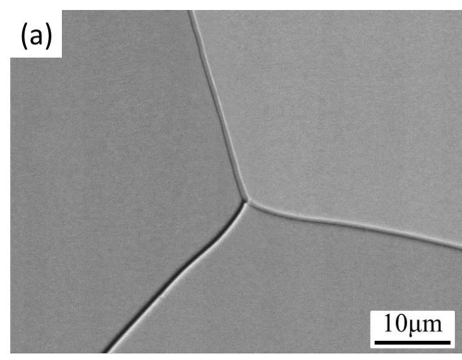

(b)

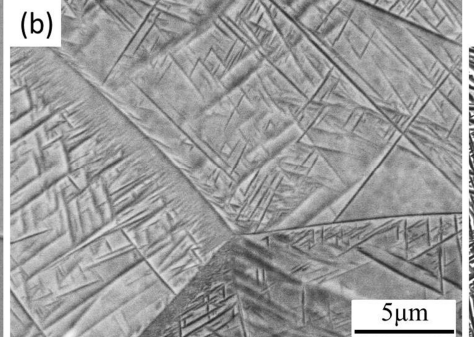

(c)

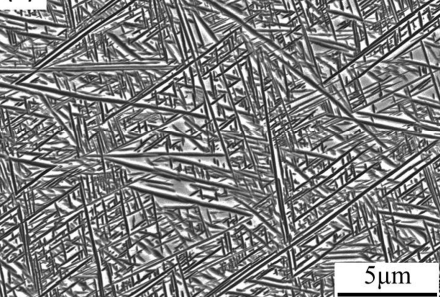

Fig. $13 \mathrm{SEM}$ images of the Ti-5553 aged at $600^{\circ} \mathrm{C}$ for (a) $1.2 \mathrm{~min}$, (b) $11.5 \mathrm{~min}$ and (c)

20min. 


\section{ACCEPTED MANUSCRIPT}
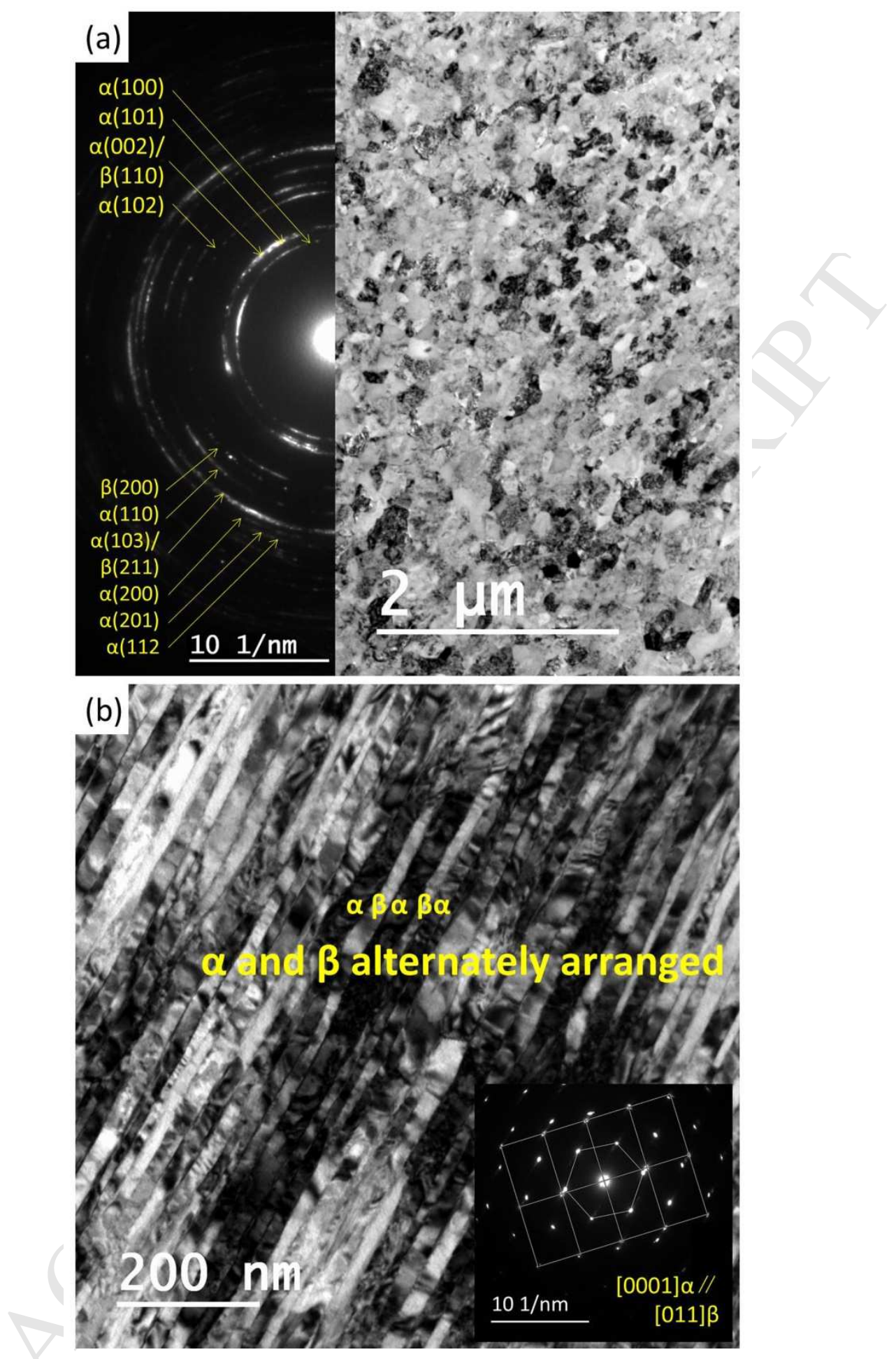

Fig. 14 TEM micrographs and SAED patterns of warm compressed Ti-5553 at $600^{\circ} \mathrm{C}$

to 0.7 at $0.001 \mathrm{~s}^{-1}$ : (a) bright field images and the SAED pattern of fine equiaxed microstructure and (b) bright field and dark field images and the SAED patterns of the lamellar microstructure. 

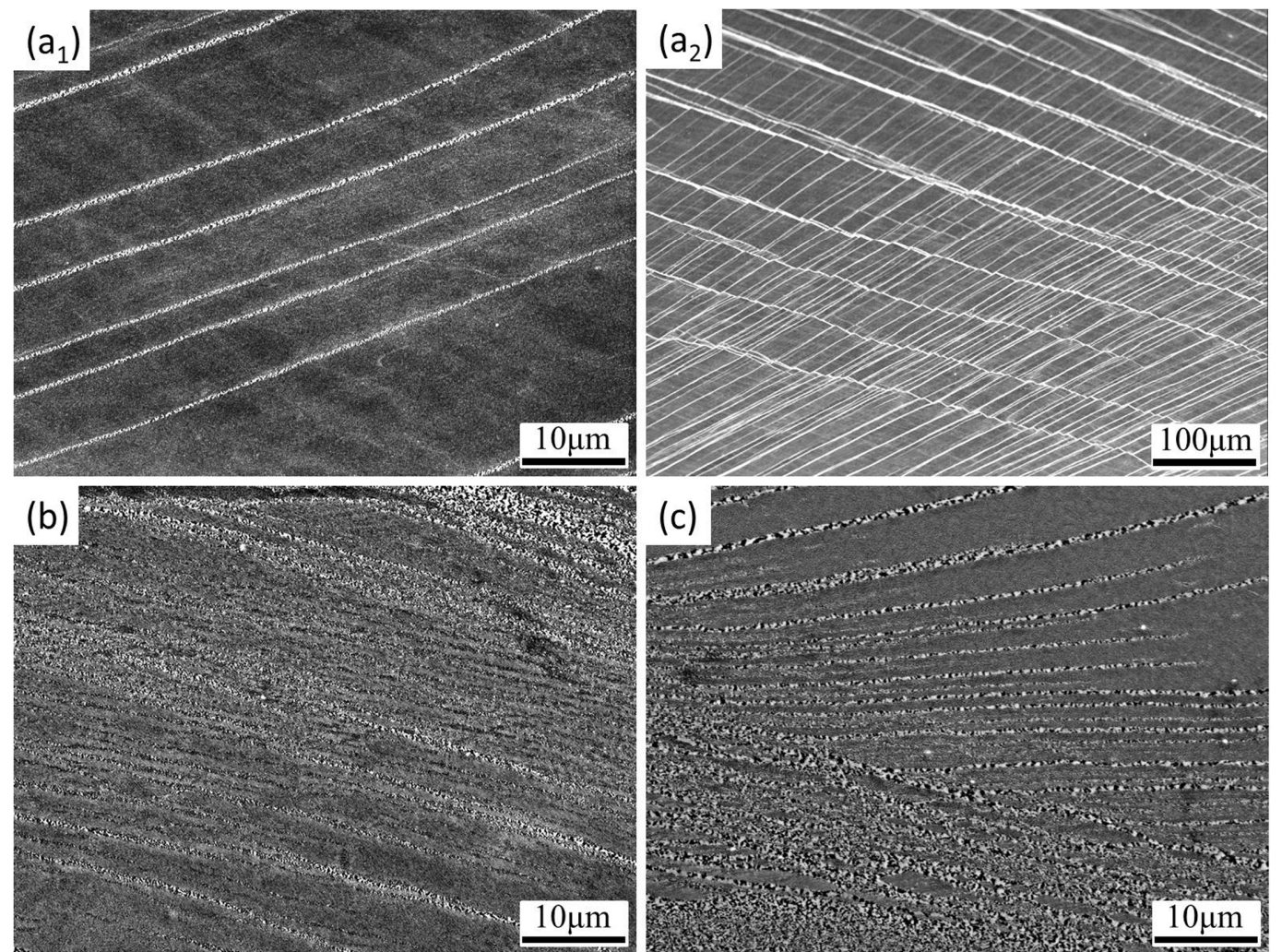

Fig. 2 SEM images of Ti-5553 warm compressed at $600^{\circ} \mathrm{C}$ to (a) 0.7 under $0.01 \mathrm{~s}^{-1}$, (b)

0.7 under $0.001 \mathrm{~s}^{-1}$ and (c) 1.2 under $0.001 \mathrm{~s}^{-1}$. 

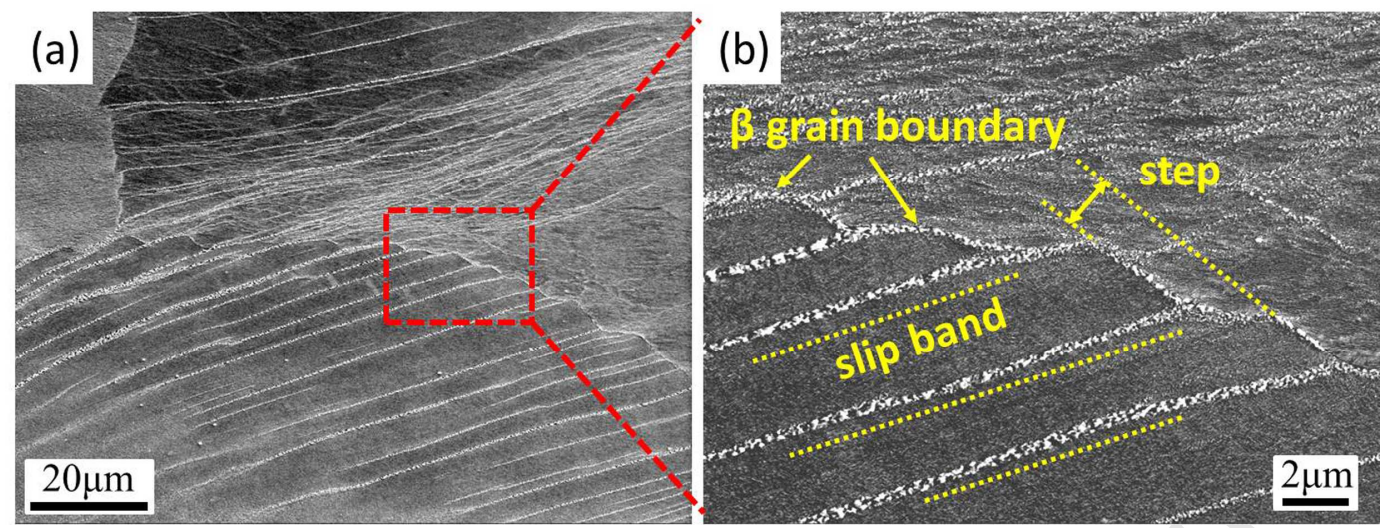

Fig. 3 SEM images of the specimen warm compressed at $600^{\circ} \mathrm{C}$ to 0.7 at $0.01 \mathrm{~s}^{-1}$. (a)

Steps formed at the intersections of the bands with the initial $\beta$ boundary and (b) a zoomed micrograph of the area outlined by the dashed box in (a). 


\section{(a)}

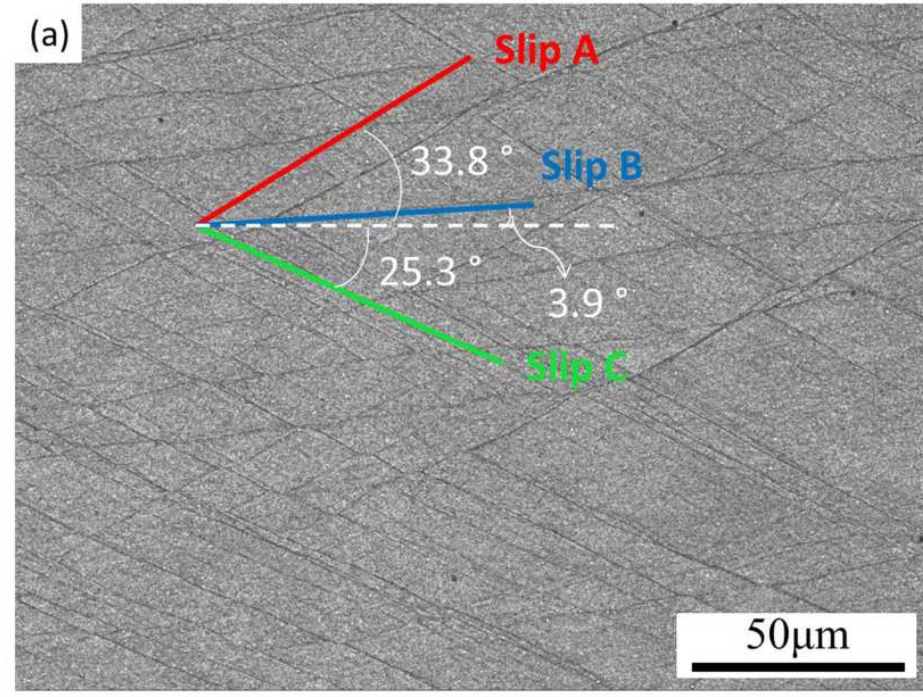

(b)

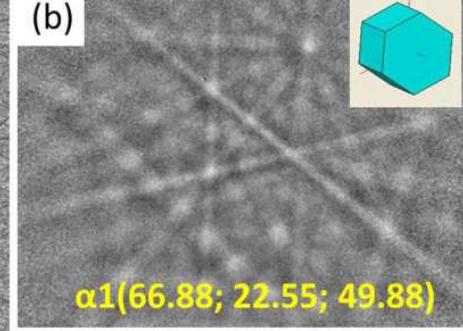

(c)

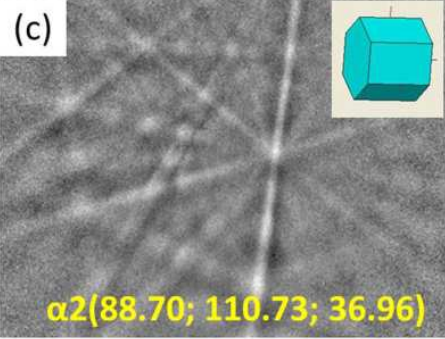

Fig. 4 (a) SEM images of Ti-5553 deformed at $600^{\circ} \mathrm{C}$ to 0.7 at $0.01 \mathrm{~s}^{-1}$ (b) Kikuchi line patterns of two distinct variants and their Euler angles. Three distinctly oriented bands are outlined in red (band A), blue (band B) and green (band C) and their inclination angles with respect to the horizontal axis are indicated with the white dashed line. 


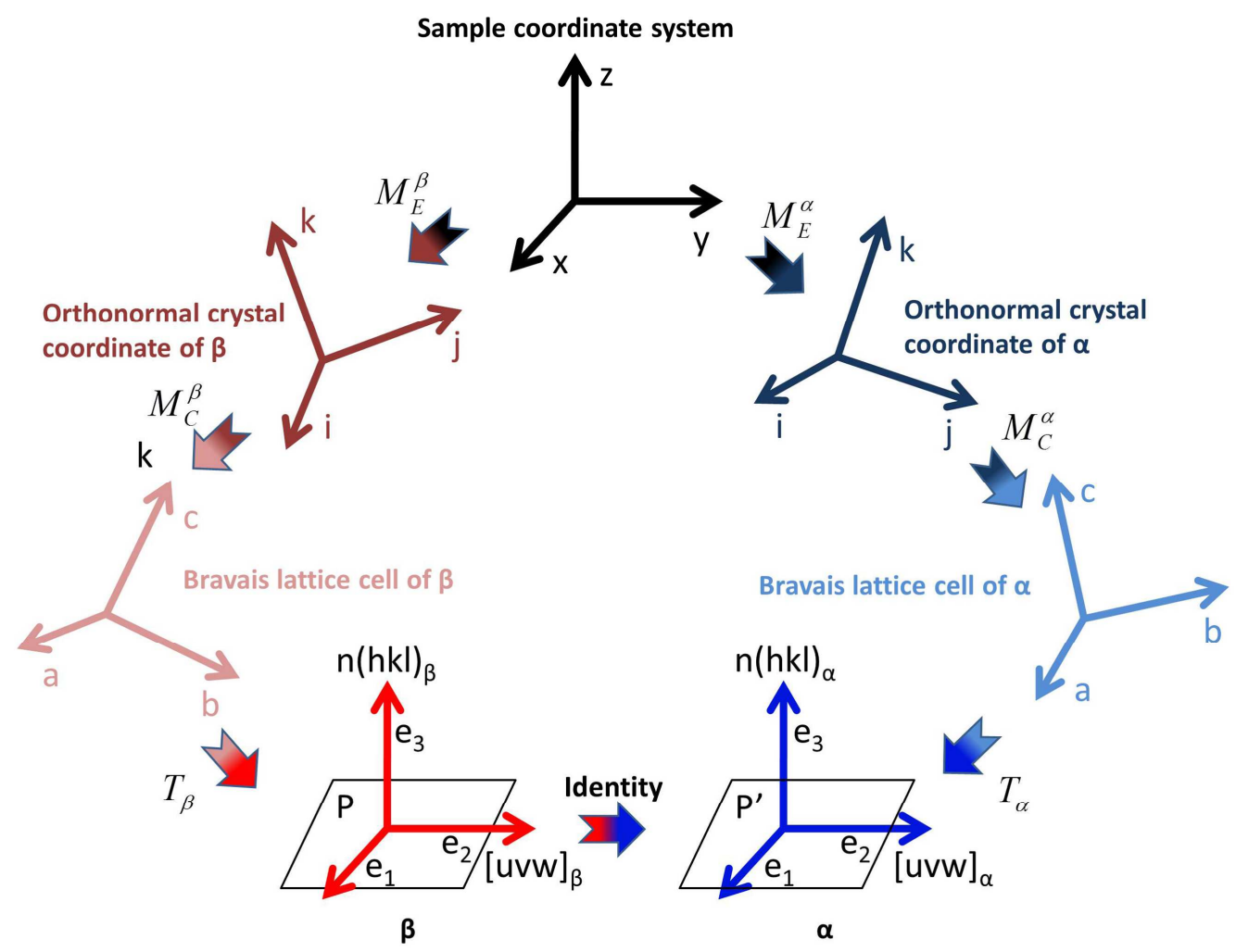

Fig. 5 Schematic illustration of the orientation relationship (OR) between $\beta$ and $\alpha$. 
(a)

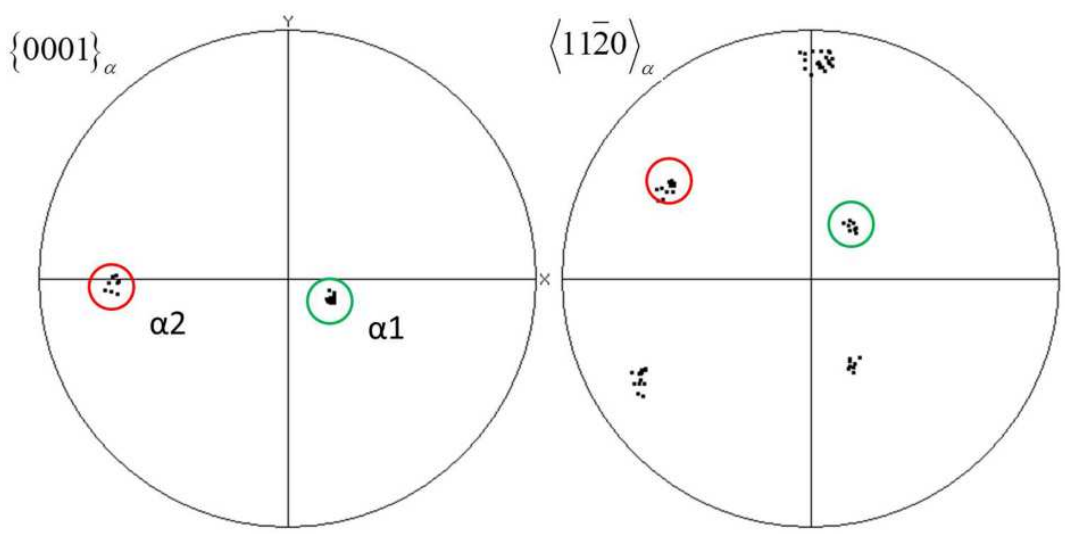

(b)

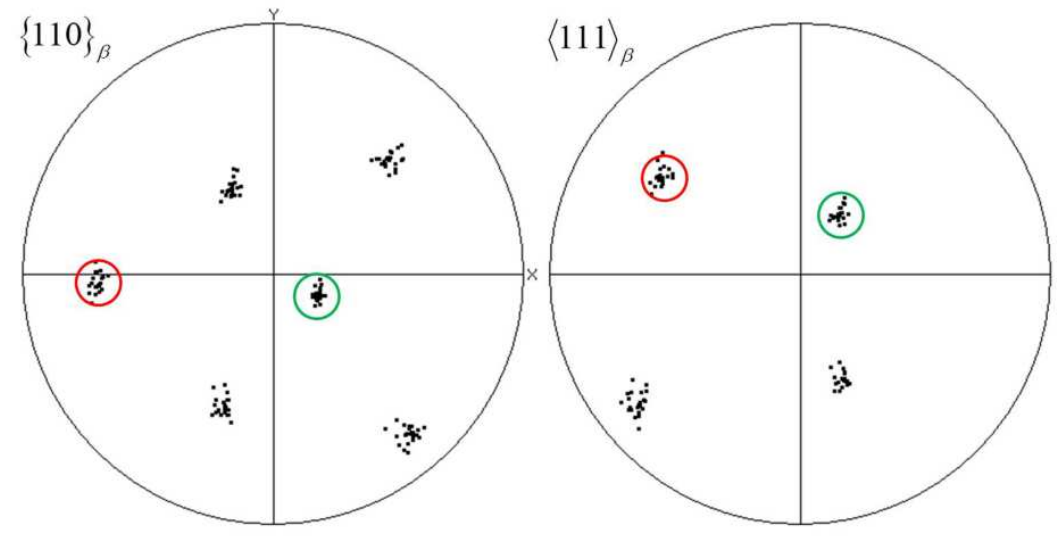

Fig. 6 (a) $\{0001\}_{\alpha}$ and $\langle 11 \overline{2} 0\rangle_{\alpha}$ poly figures of the $23 \alpha$ randomly selected in the area shown in Fig. 4(a) and (b) $\{110\}_{\beta} /\langle 1 \overline{1} 0\rangle_{\beta}$ Pole figures of the $\beta$ orientations calculated from the 23 experimental $\alpha$ orientations under BOR. 
(a)

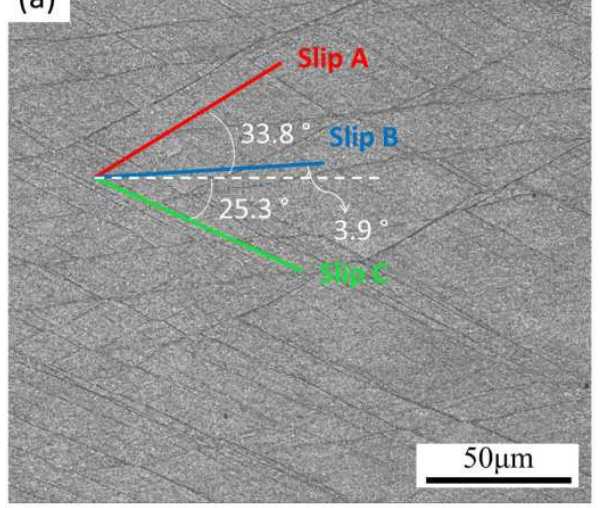

$\left(b_{2}\right)$

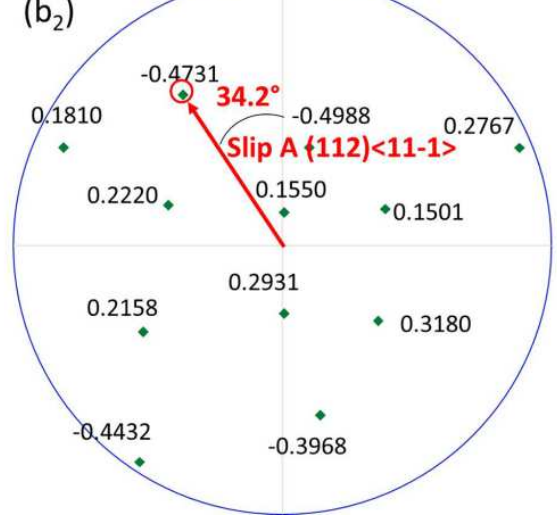

$\left(b_{1}\right)$

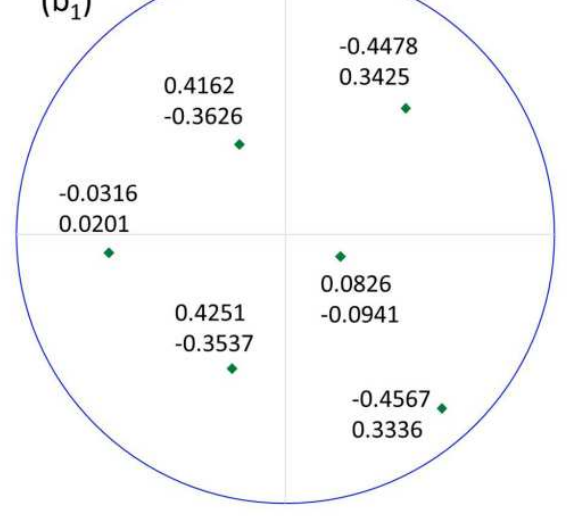

$\left(b_{3}\right)$

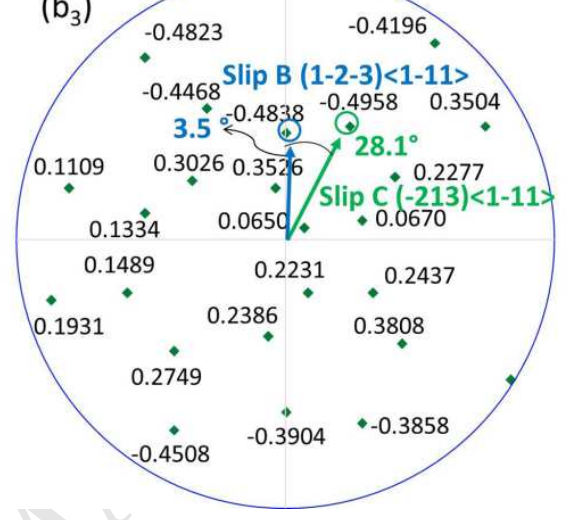

Fig. 7 (a) SEM/BSE micrograph of Ti-5553 deformed at $600{ }^{\circ} \mathrm{C}$ to 0.7 at $0.01 \mathrm{~s}^{-1}$ (b)

$\{110\},\{112\}$ and $\{123\}$ pole figures of the $\beta$ in (a). The SF values under the compression are indicated for each slip system. The slips systems correspond to the three distinctly oriented bands are circled in red, blue and green. 


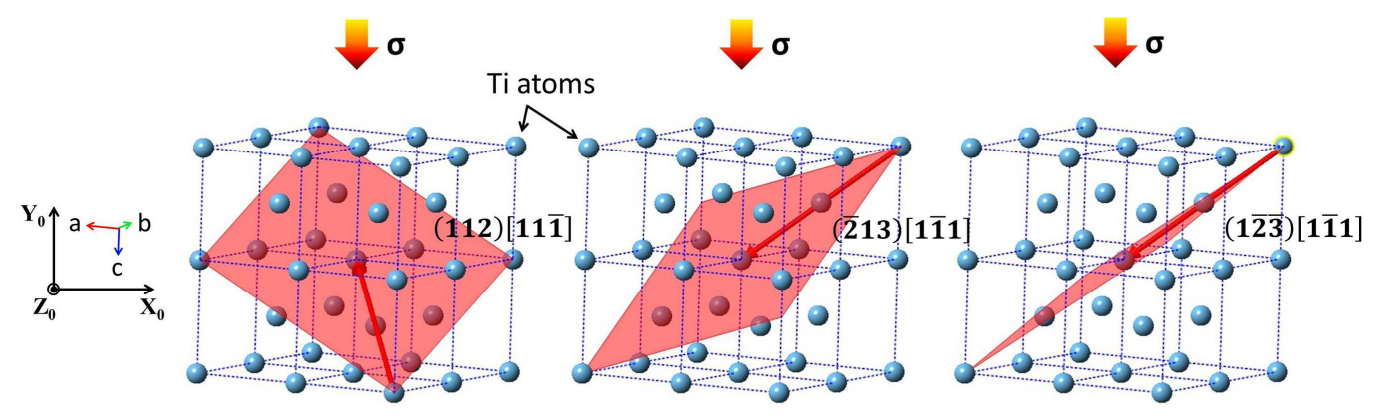

Fig. 8 The crystallographic schematic of the multi-slip systems in the single $\beta$ grain (Euler angles, $\left(179.39^{\circ}, 80.72^{\circ}, 335.06^{\circ}\right)$ ) with respect to the compressive loading. 


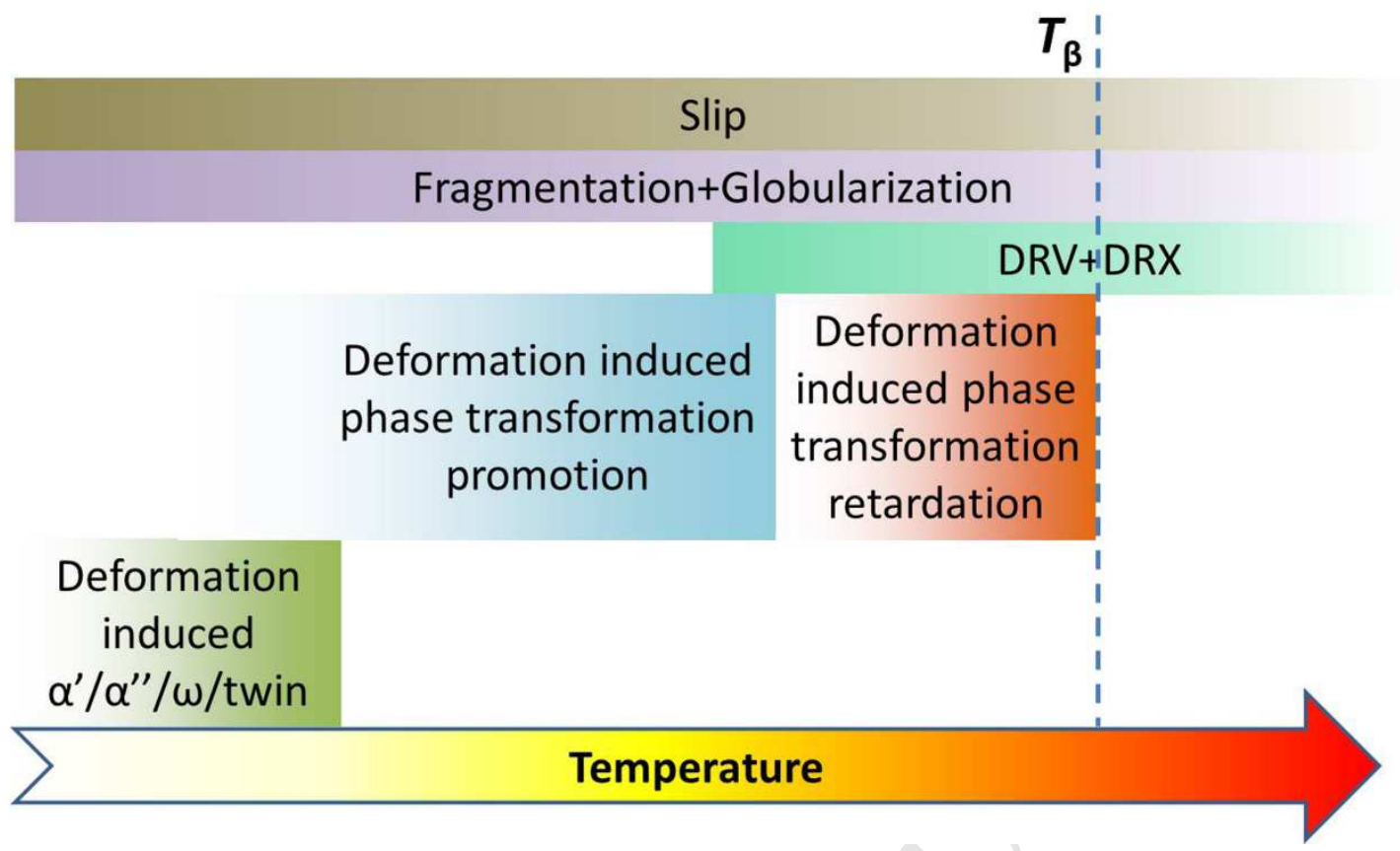

Fig. 9 Schematic diagram of deformation mechanisms of titanium alloy related to temperature. 


\section{Research Highlights:}

The multiple-slip bands were formed in Ti-5553 alloy during the warm deformation.

- Slip systems were identified accurately via crystallographic and matrix calculations.

- The hot deformation mechanisms of titanium alloys were systematically considered.

Nano/ultrafine-trimorphic structure can be successfully produced in Ti-5553. 